\title{
Cachimbos europeus de cerâmica branca, séculos XVI ao XIX: parâmetros básicos para análise arqueológica'
}

\section{Sarah de Barros Viana Hissa Tania Andrade Lima ${ }^{3}$}

RESUMO: O tabaco foi introduzido na Europa no final do século XV. Desde então, uma das formas mais comuns para o seu consumo foi o cachimbo, além do rapé, do tabaco de mascar, do charuto e, mais recentemente, dos cigarros. Os cachimbos de cerâmica branca, largamente produzidos e utilizados na Europa desde o século XV, são encontrados em sítios arqueológicos históricos ao redor do mundo, incluindo no Brasil, em decorrência do comércio internacional, que gradualmente se intensificou após o início da conquista europeia. Eles funcionam como excelentes elementos para datação de sítios e estratos arqueológicos, tendo sido estudados em vários países a partir dessa abordagem. Ainda, esse tipo de artefato, mais que fornecer datações, permite identificar redes comerciais entre nações e desenvolver discussões de cunho social e cultural. Contudo, eles foram pouco estudados no Brasil. Visando contribuir com os estudos nacionais dessa categoria material, este artigo oferece uma revisão da literatura internacional acerca do histórico da produção dos cachimbos europeus de caulim, incluindo apresentação dos principais centros produtores; da morfologia e decoração desses produtos, considerando a cronologia do fabrico; e dos métodos de análise dos diferentes cachimbos de caulim no âmbito da arqueologia histórica.

PALAVRAS-CHAVE: Arqueologia histórica. Cultura material. Cerâmica histórica. Cachimbos de caulim. Fumo.

ABSTRACT: Tobacco was introduced in Europe at the end of the 15th century. Since then, one of the most traditional means for its use has been the pipe, next to the powder version, chewing, cigars, and, more recently, cigarettes. White clay tobacco pipes, widely produced and used in Europe since the 15th century, are found in historical archaeological sites around the world, including Brazil, due to international trade, which gradually intensified with the European conquest of the New World. They are excellent guides for dating archaeological sites and layers. In addition, this type of artifact, more than a dating tool, permits identifying trading networks between nations and developing discussions of cultural and social nature. These pipes, however, have been understudied in Brazil. In order to contribute to studies of this type of artifact in our country,
1. Agradecemos à $\operatorname{prof}^{a}$. $\mathrm{Dr}^{\mathrm{a}}$. Hannedea Meerkerk (MOWIC Foundation) pelo auxílio com algumas referências holandesas e ao prof. Dr. David Higgins (Universidade de Liverpo$\mathrm{ol}$ ), pelas informações gentilmente concedidas sobre a produção inglesa de cachimbos de caulim.

2. Doutoranda em Arqueologia (Museu Nacional/ UFRJ) e mestre em Antropologia, linha de pesquisa $\mathrm{Ar}$ queologia Histórica (UFMG). Arqueóloga no IPHAN-MG. E-mail: <sarah. hissa@gmail.com>.

3. Professora do Departamento de Antropologia do Museu Nacional, Universidade Federal do Rio de Janeiro. Pesquisadora do Conselho Nacional de Desenvolvimento Científico e Tecnológico - CNPq. E-mail: $<$ talima8@gmail.com>. 
4. Zarankin (2007), Hissa (2012) e Richie (1978) this paper offers a revision of the international literature on the history of clay pipe production in Europe, including the presentation of main production centers; morphology and decoration of these products, considering issues of fabrication chronology; and the methods used in Historical Archaeology for analyzing clay tobacco pipes.

KEYWORDS: Historical Archaeology. Material culture analysis. Chronology. Ceramics. White clay tobacco pipes. Smoking.

1. Introdução

Na Europa, cachimbos de caulim foram largamente produzidos e utilizados por aristocratas e burgueses como também por trabalhadores e operários, seguindo distinções sociais atribuídas aos vários tipos desse objeto. Seu uso foi associado à contemplação e ao lazer nas classes dominantes e ao trabalho e festejos nas classes subalternas. Contudo, o uso desses cachimbos manufaturados não se restringiu àquele continente, e seu comércio atingiu dimensões globais. Eles foram utilizados em permutas nas Américas e em escambo de escravos na África. Fizeram parte dos objetos cotidianos nas colônias inglesas ao redor do mundo - dos EUA à Austrália -, das colônias holandesas, portuguesas e espanholas. Marinheiros europeus os utilizavam em larga escala e os exploradores e "operários do mar" carregavam-nos consigo em expedições ao Ártico no século XVIII ou à Antártica, no XIX. ${ }^{4}$ Eles aparecem também em sítios históricos brasileiros, justificativa principal deste artigo.

$\bigcirc$ estudo de cachimbos de caulim, à maneira de outros itens de produção europeia (como as faianças e os vidros), permite mapear e discutir relações econômicas de troca e comércio em larga e pequena escalas, tal como preferências socioculturais ou possibilidades econômicas. Contudo, há aqui uma especificidade. Enquanto comer e beber sempre fizeram parte da existência humana, a propagação do cachimbo na Europa se dá concomitantemente com a difusão de uma prática nova naquele continente e unicamente sociocultural, o ato de fumar. Nesse sentido, inaugura-se a disseminação global não somente de tipos de objetos para fumar, mas de toda uma prática.

artigo que se inicia apresenta uma revisão bibliográfica, voltada para embasar a identificação de materiais e discussões circundantes. Ele inclui uma descrição da produção dos cachimbos de caulim, de tipos de cachimbos, considerando sua morfologia e decoração, e os métodos principais utilizados no estudo arqueológico desses objetos. Para tal, a nomenclatura das partes de um cachimbo utilizada neste trabalho é a disposta na Figura 1. 


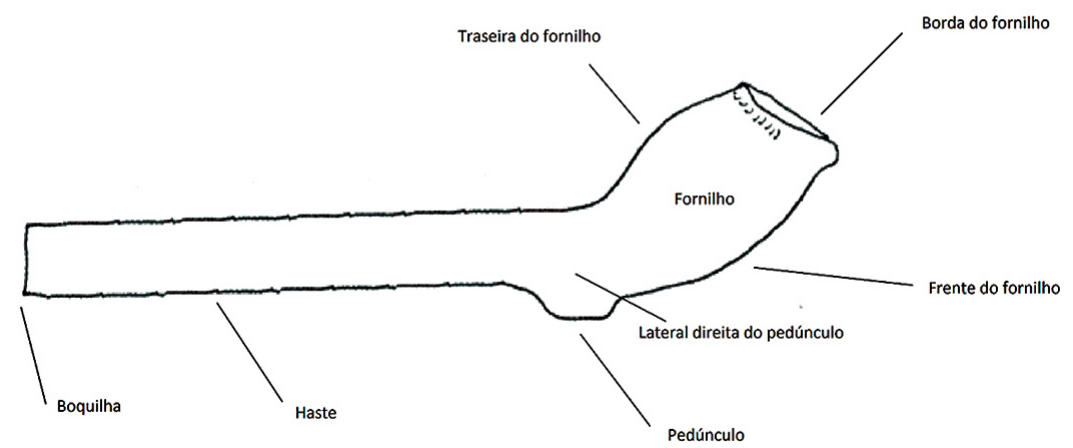

Figura 1 - Partes de um cachimbo e a nomenclatura adotada neste artigo. Autoria da imagem: Sarah Hissa.
5. O termo argilomineral define minerais filossilicatos, constituídos por silicatos hidratados de alumínio e ferro, que podem conter pequenas quantidades de elementos alcalinos $(\mathrm{K}, \mathrm{Na}$, Li) e alcalinoterrosos (Ca, MG). Existem cerca de 40 argilominerais. São eles os componentes que conferem plasticidade às argilas (Mello et al., 2011).

6. Coelho, Pérsio de Souza Santos; Helena de Souza Santos (2007).

7. Jepson; Rowse (1975).

8. Rice (1987, p. 45).

2. Cachimbos históricos de caulim: contexto de produção

\subsection{As argilas brancas de caulinita}

Os cachimbos dos quais trata este texto eram feitos com argilas de caulim. A etimologia da palavra caulim é frequentemente atribuída ao vocábulo chinês kauling (colina alta), sendo a designação comumente usada para a argila composta pelo argilominera $\left.\right|^{5}$ caulinita. ${ }^{6}$ Uma classificação possível das argilas é a mineralógica, que leva em conta os argilominerais. $\bigcirc$ grupo caulim (Kaolin Group) agrupa os filossilicatos (estrutura de ordenamento regular, em camadas) de duas camadas (uma de tetraedros de sílica e outra de octaedros de alumina), incluindo a caulinita, nacrita e dickita. A caulinita, que nos interessa diretamente aqui, é composta por silicatos hidratados de alumínio, sendo a composição química ideal desse argilomineral $\mathrm{Al}_{2} \mathrm{Si}_{2} \mathrm{O}_{5}(\mathrm{OH})_{4}{ }^{7}$. Essas argilas são provenientes da degradação normalmente de rochas ácidas, como pegmatitos (rochas graníiticas com feldspato e quartzo) e xistos micácios. É interessante o fato apresentado por Prudence Rice ${ }^{8}$ de que a lixiviação ácida e a alta drenagem dos solos em áreas tropicais e temperadas, onde essas argilas são mais frequentemente encontradas, removem outros elementos, deixando apenas a sílica e alumina. A argila decorrente desse processo, portanto, apresenta baixo ou nulo teor de elementos corantes, como o ferro.

A argila caulinítica, de modo geral, é macia e geralmente branca lou levemente rosada, a depender da presença de algum teor de ferro). Apresenta baixa capacidade de troca de cátions, partículas de tamanho moderado a grande, e baixa capacidade de expansão-retração. São as grandes partículas que conferem sua baixa plasticidade e baixa capacidade de retração durante a secagem. Essa característica das argilas cauliníticas é útil no processo de secagem da pré-forma do cachimbo, uma vez que as receitas utilizadas dão preferência à baixa retração, 
9. Possivelmente, a etimologia da palavra caulim provém do local de formação dessas argilas, no caso de desagregação in situ.

10. Adianta-se que os cachimbos de caulim eram queimados em altas temperaturas, por volta dos 1000oC.

11. Shepard (1985, p. $105-$ 107).

12. Duco (1980a).

13. A bone china não deve ser confundida com a kaolin/chinaclay ou com a ballclay. A bone china resulta de uma mistura artificial entre ballclay, china clay e cinza de ossos. Esta foi desenvolvida na Inglaterra no final do século XVIII. para evitar a deformação da peça antes da queima. Por outro lado, é importante que a argila de caulim tenha alguma plasticidade para o fabrico de cachimbos, pois, se for demasiado pouca, a peça poderá quebrar durante a moldagem.

Depósitos cauliníticos podem ser provenientes da alteração in situ (residuais) de rochas ou serem depósitos sedimentares secundários. ${ }^{9}$ As argilas primárias, em função de maior granulação, geralmente apresentam mais baixa plasticidade e mais baixa capacidade de retração do que as provenientes de depósitos secundários. Ainda, apresentam mais impurezas provenientes da rocha matriz. Por outro lado, os depósitos secundários, em função da sua granulação menor (efeito do transporte), geralmente oferecem maior plasticidade. Eles também apresentam menos impurezas da rocha matriz e podem apresentar matéria orgânica (por ex., ambientes lacustres).

Ainda, como as argilas de caulim têm muita alumina e resistência para absorver impurezas, elas são relativamente refratárias, o que se relaciona diretamente à temperatura de queima (alta, no caso das cauliníticas) ${ }^{10}$ e ao fato de que permanecem porosas após a queima. $\bigcirc$ grau de porosidade varia de acordo com a temperatura de queima (ex. $45-50 \%$ de porosidade em queima de $950^{\circ}$ e $30-40 \%$, a $1300^{\circ}$ ). Isso é relevante no caso dos cachimbos, quando se lembra de que a porosidade da boquilha gruda na boca do fumante e por vezes é coberta por esmalte ou resina.

Sobre a queima das argilas brancas, Anna Shepard"1 aponta que, se a cerâmica é branca, não é possível determinar de forma contundente o tipo de atmosfera de queima, podendo indicar argila sem óxido de ferro, o que é raro na natureza, ou atmosfera oxidante na queima de argilas com algum teor de elemento passível de ser oxidado ou reduzido, no caso de uma queima em ambiente redutor. Se a cerâmica é acinzentada, poderá ter sido originada de uma argila com baixo teor de óxido de ferro que teria sido reduzida (ou sofrido oxidação incompleta), ou, ainda, uma argila branca levemente esfumaçada, com a deposição de carbono e sua redução. Ainda, se a cerâmica apresenta coloração creme, poderá indicar uma queima oxidante de argilas contendo algum teor de óxido de ferro.

Outro ponto que se levanta a partir do apresentado por Shepard é que, em se tratando de queima aberta em atmosfera redutora, a fumaça poderá resultar na deposição de carbono no material e na alteração de cor na cerâmica. De forma análoga, a ausência de carbono na cerâmica sugere que condições oxidantes poderão ter prevalecido, ao menos no final da queima. Decerto, os cachimbos de caulim não foram produzidos em queima aberta, mas em fornos de alta temperatura. Além disso, o emprego das saggars ou os muffles - recipientes cerâmicos refratários - tinha a função, além de acondicionar as peças para queima, evitar contato entre a fumaça (entre outros elementos) e o produto. Contudo, interessa apontar também que eram produzidos em menor escala cachimbos de caulim com a superfície deliberadamente preta, que eram enegrecidos pela adição de carbono na sua superfície durante a queima. Se requeimados, voltavam à cor branca. ${ }^{12}$

Entre os tipos de argila branca com base na caulinita, destacam-se, para os interesses da arqueologia histórica, a china clay e a ball clay. ${ }^{13}$ 
A designação china clay decorre da sua larga apropriação para manufatura de whitewares e porcelanas. Esse é o termo usado geralmente para os depósitos primários de argilas de caulim, provenientes da alteração hidrotermal de granitos. Termos alternativos da china clay são kaolin clay llembrando novamente a etimologia da palavra kauling ser colina altal e porcelain clay. A china clay foi explorada na China desde o século IX, mas, apesar das várias tentativas para encontrar esse tipo de argila na Europa, ela só foi encontrada na Inglaterra no início do século XVIII. Os depósitos dessa argila em Devon e na Cornualha, na Inglaterra, foram encontrados pela primeira vez em 1746, de quando data também a primeira porcelana inglesa. Nessa época foram descobertos depósitos de china clay nos EUA e na França. Foram identificados também depósitos próximos a Glasgow, Escócia. ${ }^{14}$

Já a chamada argila de bola, ou ball clay ${ }^{15}$, recebeu sua designação em decorrência do método antigo de tratar a argila. Ela era cortada em cubos de cerca de 230 milímetros, que, com a retração, posteriormente se transformavam em pequenas esferas. Os principais componentes da ball clay são, normalmente, caulinita, mica ou sericita e quartzo fino. Outra descrição encontrada cita a presença de sílica, caulinita e muscovita. Esses elementos também ocorrem na china clay, mas a ball clay apresenta maior teor de titânio.

A ball clay é uma argila de deposição secundária, de modo que os grãos são mais finos e, consequentemente, a argila é mais plástica. Retrai-se bastante se comparada à china clay. Como apresenta maior maleabilidade antes da queima, era mais adequada para a produção de cachimbos que a china clay. Diante disso, a maior diferença entre o caulim presente na ball clay e na china clay é o tamanho da partícula e o grau de ordenamento dentro da estrutura cristalina. Além disso, em decorrência das características dessas duas argilas no tocante à porosidade, vitrificação e cor, a china clay era tipicamente mais utilizada para produtos de melhor qualidade, como a porcelana, enquanto a ball clay foi mais comumente utilizada em produtos de menor qualidade, como é o caso dos cachimbos, altamente descartáveis. Por outro lado, as china clays, por apresentarem partículas maiores e inclusões, requerem mais esforço na trituração e peneiramento do que as ball clays.

Uma informação interessante sobre o tratamento da argila é que algumas ball clays podem ser lustradas ao esfregar os dedos enquanto ainda úmidas, sendo que o brilho é mantido após a queima. ${ }^{16}$ Testes feitos por Shepard com ball clays temperadas com vários tamanhos de desengordurantes e com outras argilas indicam que o acabamento de superfície depende fortemente de alguns elementos combinados. Para o nivelamento da superfície de uma argila, deve-se considerar: o tamanho do tempero, que, se grande, o aplainamento desta será mais difícil; a granulometria da pasta; sua capacidade de retração, que, se alta, pode deixar grãos protuberantes; o ponto de secagem. $\bigcirc$ resultado de não atentar corretamente para esses atributos poderá ser grãos protuberantes, sulcos ou buracos. Isso é relevante para o caso do processo de produção do cachimbo, pois, apesar de se tratar de um objeto manufaturado industrialmente, este incluía prévias etapas artesanais, como é o caso da preparação da pasta e do polimento.
14. Para mais informações sobre a china clay, ver Bristow; Scott (2002), Rice (1987), Shepard (1985), Sudbury; Gerth (2011).

15. Vince e Peacey (2006) usam, para designar a ball clay, principalmente o termo pipe clay e apontam que também podem ser referidas pela designação seatearth, que considera sua formação geológica.

16. Shepard (1985). 
17. White, A (1975).

18. Vale apontar, a título de curiosidade, que Josiah Wedgwood foi avô de Charles Darwin.

É importante ressaltar que a receita exata utilizada por cada produtor variava. White ${ }^{17}$ aponta, usando o exemplo de Lancaster, que algumas receitas para cachimbos misturavam ball clay e china clay. Contudo, como a china clay foi descoberta somente em meados do século XVIII na Inglaterra, é presumível que, ao menos até aquele momento, misturas contendo somente ball clays tenham sido utilizadas.

Ainda, as misturas foram particulares, tanto de cada período como de cada produtor, sendo cuidadosamente planejadas. Se a argila for curta, ou seja, pouco plástica, o cachimbo poderá quebrar durante a moldagem. Argilas muito gordas, ou seja, excessivamente plásticas, irão encolher muito e deformar o cachimbo. Se estiver muito dura, demandará muito esforço do artesão. As argilas com muita inclusão de talco resultarão em um produto muito poroso.

A importância da ball clay para a produção de bens de consumo na Inglaterra é tal que, em 1663, é feita uma restrição inglesa a sua indústria exportadora de ball clay. Essa restrição foi retirada somente na segunda metade do século XIX, quando o país então se tornou exportador rentável dessa argila.

Apesar da existência de outras jazidas, a produção significativa de ball clay na Inglaterra se deu em Dorset e Devon, bacia hidrográfica do rio Bovey, no sudoeste da Inglaterra. As argilas provenientes de depósitos secundários, como é o caso dessa ball clay do sudoeste da Inglaterra e Wiltshire, eram de melhor qualidade que outros tipos, como a argila associada a depósitos de carvão/hulha (coal mesure clay) (como jazidas de Staffordshire e Shropshire). A exploração de ball clay na bacia do Bovey começou no final do século XVII, associada estreitamente à produção dos cachimbos. Durante o século XVIII, essas argilas foram gradualmente se tornando mais utilizadas e a extração de argila aumentou, para corresponder ao crescimento da demanda também por outros produtos cerâmicos, inicialmente na área de Londres e posteriormente em Staffordshire (onde se destaca a indústria cerâmica fundada por Josiah Wedgwood ${ }^{18}$ em 1759). Devon também supriu Chester, Bideford, Bridgewater, Bristol, Gloucester, Liverpool, Padstow e Swansea, da costa do País de Gales até Chester.

Poole e a ilha de Wight, jazidas também de grande importância, supriram portos desde o estuário de Helford na Cornualha até o norte em Newcastle. Fabricantes da região de Portsmouth (incluindo Gostport, Portchester, Fareham) utilizavam-se de argila proveniente da ilha de Wight durante o século XVII, mas essas jazidas foram abandonadas em favor de outras melhores no oeste da Inglaterra, já no século XIX. Northampton Fields era uma jazida também de qualidade, em 1705, mas as de Poole e da itha de Wight eram consideradas melhores.

A bibliografia revisada neste artigo, todavia, oferece algumas informações conflitantes quanto à utilização de jazidas específicas por cada um dos centros produtores. Para Vince e Peacey, os fabricantes de cachimbo de Londres usavam, em um primeiro momento, exclusivamente argilas provenientes de Poole e da itha de Wight. Ayto já aponta que usavam argilas provenientes da Cornualha, de Devon e de Dorset. Oswald aponta para a utilização de argilas das localidades Dorset, itha de Wight e Kent (de acordo com um monopólio de venda de argila concedida a Philip Foote em 1618), posteriormente Poole. Apesar das discordâncias, em todos 
os casos, tratava-se de argila adquirida de fontes relativamente distantes do centro produtor. Já entre os séculos XVII e XVIII, os produtores londrinos usavam principalmente argilas provenientes da Cornualha, de Devon e de Dorset.

Argilas também eram levadas das regiões de Purbeck, Thanet, ilha de Wight e Poole para Totterdam, Hull, Nottinghamshire, Lynn e Irlanda, no século XVI. Jazidas menores localizavam-se nos arredores das cidades de Broseley, em Shropshire, e Amesbury, em Wiltshire, e supriam produtores locais. Aponta-se também a jazida de Chitterne, em Wiltshire, sendo explorada certamente no século XVII. Outras localidades onde há jazidas de ball clay no Reino Unido são Staffordshire, Lancashire, Yorkshire, Leicestershire, South Derbyshire, North Somerset, South Lincolnshire e Oxfordshire/Buckinghamshire. ${ }^{19}$

Na Holanda, não há jazidas de argila branca, de modo que se tornou necessária a sua importação para produção dos cachimbos. Assim, desde o início do século XVII importou-se ball clay da Inglaterra. Como os primeiros fabricantes de cachimbos na Holanda eram ingleses refugiados (ponto que será detalhado adiante), eles continuaram adquirindo a argila de onde estavam acostumados no seu país de origem. No decorrer do século XVII isso mudou. A partir da década de 1630 os fabricantes de Gouda e Roterdã (dois dos maiores centros produtores da Holanda) começaram a importar de Colônia, na Alemanha, e de Tournai, na Bélgica, de modo que a argila inglesa se tornou gradualmente menos utilizada até o ponto em que era incluída somente em misturas. Nos séculos XVIII e XIX, a argila de Andenne, na Bélgica, tornou-se mais importante. Isso decorreu da introdução de cachimbos mais longos (churchwarden) e da consequente necessidade de uma argila mais resistente. Para isso, misturava-se a argila de Andenne com a argila alemã. ${ }^{20}$

Já nos EUA, foram descobertas jazidas de ball clay somente no final do século XIX, em 1880, no leste, centro-oeste e sul do país. Até então a ball clay usada por ceramistas estadunidenses provinha de Devonshire, Inglaterra. ${ }^{21}$

Nesta seção, buscou-se contextualizar a complexidade da primeira etapa do processo produtivo dos cachimbos de caulim, a escolha da argila. Como as propriedades dessa argila têm relação direta com as técnicas de produção e as características de performance dos cachimbos, a serem descritas mais adiante, mesmo a busca por argila envolvia muitos conhecimentos técnicos acerca da matéria-prima e o resultado almejado. Trata-se de uma relação extremamente próxima, entre o tipo de argila, o tipo de produto que se pretende fabricar e os passos do processo de produção.

Por fim, foram também expostas algumas das dificuldades que os pesquisadores devem enfrentar na busca em determinar a proveniência das argilas a partir de análises arqueométricas, uma vez que argilas de jazidas diferentes podem estar misturadas em um único produto.

\subsection{Principais centros produtores de cachimbos de caulim da Europa}

Os cachimbos de caulim foram produzidos, em um primeiro momento, na Inglaterra. ${ }^{22}$ A popularidade dos cachimbos ingleses teria então rapidamente se
19. Para mais informações sobre jazidas de argila ball clay na Inglaterra, ver Ayto (2002), Bristow; Scott (2002), Fox; Hall (1979), Oswald (1975), Sudbury; Gerth (2011), Vince; Peacey (2006).

20. Para mais informações sobre a ausência de jazidas de argilas brancas na Holanda, ver Duco (1980a).

21. O recorte deste artigo abarca os cachimbos de caulim de produção europeia. Contudo, algumas informações sobre a produção estadunidense serão oferecidas, como parte do contexto de relações globais criadas em torno deste produto, como se verá adiante. Para mais informações sobre jazidas de argila nos EUA, ver Sudbury; Gerth (2011, p. 20).

22. Essa informação é consensual na bibliografia especializada, tanto inglesa quanto holandesa. Para mais informações, ver Ayto (2002), Duco (1980a), Higgins (2009), Oswald (1975). 
23. Segundo Oswald (1975), o primeiro produtor na $\mathrm{Di}$ namarca iniciou seus trabalhos em 1655.

24. Na Suíça, tornou-se popular o cachimbo de metal, de modo que a produção do cachimbo de caulim inicia-se somente no final do século XVII.

25. Para mais informações sobre essa fábrica, ver Gojak; Stuart (1999).

26. Para mais informações sobre os primeiros cachimbos ingleses, ver Oswald (1975).

27. Oswald (1967); Higgins (2009)

28. Walker (1970).

29. Oswald (1967). espalhado pela Europa continental, em especial para a Holanda e Alemanha (Halle, Kamenz, Leipzig), mas também para a França, Dinamarca, ${ }^{23}$ Suécia, Suíça ${ }^{24}$ (em especial a cidade de Zug) e Praga, locais que se tornaram também centros de produção.

Deve-se lembrar de que, de modo geral, a dimensão dos centros fabricantes varia de portes extremamente pequenos, com um único fabricante ou produções familiares, a grandes firmas exportadoras, que empregavam centenas de pessoas. Um exemplo de uma dessas grandes fábricas é a exportadora escocesa William White que, em 1900, produzia 606 tipos distintos de cachimbos. ${ }^{25}$ Contudo, mais frequentemente e certamente no início da indústria de cachimbos na Europa, os produtores eram pequenos artesãos, organizados em produções familiares, que atravessavam várias dificuldades no fabrico e venda, entre aquisição da argila, obtenção de permissões de produção, custos de fornos adequados até distribuição do produto final. Por essas razões, muitos deles localizaram-se em cidades portuárias. Além disso, os fabricantes de cachimbo na Inglaterra ao longo dos séculos XVII e XVIII, buscavam sanar em parte essas dificuldades pela intensa mobilidade, levando ou não consigo suas famílias.

A seguir, serão apresentados os principais centros produtores para os quais se conseguiu suporte bibliográfico, iniciando-se pelo Reino Unido e Irlanda, por sua produção anteceder às demais.

\subsection{Reino Unido e Irlanda}

Informações em relatos históricos para o consumo do tabaco na Inglaterra sugerem que a produção inglesa de cachimbos já era existente em 1573. Contudo, o primeiro registro documental sobre a indústria data de 1601 e sobre um produtor específico de cachimbos, de 1603. ${ }^{26}$ As estimativas de Oswald apontam para a existência de, ao menos, 3.400 fabricantes mapeados em toda a história da produção inglesa, o que seria, segundo o referido arqueólogo, cifra ainda mais baixa que a realidade. Higgins, em estudo mais recente, já aponta um número bem mais alto: acima de 10.000.27

A maior parte dos cachimbos mais antigos (séc. XVI e início do XVII) foi encontrada em Londres, que teria sido um dos primeiros centros, ao lado de Plymouth e Bristol. Eles teriam imitado em algum grau a forma dos cachimbos ameríndios da Virgínia, EUA, porém em escala menor. ${ }^{28}$ Alguns desses cachimbos mais antigos foram inclusive encontrados arqueologicamente na Irlanda, Holanda e Suécia, atestando tal comércio recuado do produto. ${ }^{29}$ Outros produtores desse período localizavam-se em Taunton, Chester e Salisburgo.

A distribuição dos centros produtores se transforma com o passar do tempo, conforme mapas elaborados por Davey e Tomlinson e Oswald. Nota-se uma concentração inicial na costa sul da Inglaterra na primeira metade do século XVII, seguida por uma intensificação na produção da região de Bristol, na segunda metade do XVII. Já na primeira metade do XVIII, ocorre um leve fortalecimento de produtores nas porções internas da ilha, seguido, na segunda metade do XVIII, por 
uma retração da indústria como um todo. Na primeira metade do XIX, ocorre um restabelecimento da indústria e aumento da produção na costa oeste, região de Chester e Liverpool.

Esse mapeamento da evolução da distribuição de centros produtores pode ser mais bem detalhado, especialmente no que se refere às razões sóciohistóricas para suas expansões e retrações. Sobre as primeiras décadas da produção de cachimbos na Inglaterra, a preponderância que os fabricantes da região de Londres e Westminster detinham fora conquistada por meio de monopólios concedidos à Corporação The Tabacco Pipe Makers Company, instituída em 1619. A corporação excluía centros como Bristol e York, que tinham suas próprias ligas. Segundo Oswald, esta parece ter exercido controle apenas moderado e certamente menor que a Corporação de Gouda, na Holanda. Em 1619, James 1 confere aos produtores da região londrina um monopólio de produção. Outros tipos de monopólio conferidos a esses produtores na primeira metade do XVII restringiam a compra de certas argilas de qualidade somente aos favorecidos e a entrada de tabaco no país somente pelo porto de Londres. Esses e outros privilégios resultaram na força dos produtores de Londres e Westminster na primeira metade do XVII, apesar das infrações cometidas nos centros de Broseley, Bristol e York. ${ }^{30}$

Já na segunda metade daquele século, os monopólios são quebrados e as outras regiões puderam se desenvolver mais livremente. Com a abertura dos demais portos, Bristol, também cidade portuária, ultrapassa Londres em produção em fins do XVII, tal como Liverpool. Southampton, cidade também portuária no sul da Inglaterra, foi grande produtora, distribuindo cachimbos tanto na Inglaterra quanto globalmente. Sua produção vai desde 1618 até o final do século XIX, com maior período de pico produtivo entre 1700-1750, pela alta quantidade de famílias produtoras instaladas na localidade. Na região do porto de Portsmouth, sul da Inglaterra, as localidades de Fareham, Portchester, Gosport e Portsmouth produziram cachimbos em momentos distintos: Fareham, desde c. 1711 ; Portchester, desde meados do XVIII; Gosport, de meados do XIX; e Portsmouth, de produção mais antiga, desde 1620. Em 1770, Liverpool já exportava cerca de um milhão de cachimbos, enquanto Bristol exportava 2.386 caixas de cachimbos (estima-se que esse valor signifique entre 4 e 5 milhões de unidades), quantidade dobrada no início do XIX. ${ }^{31}$

Como se vê, a maior parte dos cachimbos comercializados na Inglaterra provinha de cidades portuárias, tais como Londres, Bristol e Liverpool. Contudo, já no século XIX, o sistema de transporte terrestre permitiu que outras cidades desenvolvessem mais sua produção/distribuição, sendo que Broseley, em Shropshire, se tornou um grande centro. A região é próxima de jazidas de argila branca, conforme já mencionado, e também de material combustível, o que facilitou o desenvolvimento da indústria. $\bigcirc$ pico da sua produção se deu ao final do XVII, notadamente com produtos de qualidade. Entre outros tipos, produzia cachimbos de haste longa em meados do XIX, sendo sugerido que o termo churchwarden tenha sido cunhado nessa localidade. Inclusive atribuiu-se a alcunha "Broseley pipes" para
30. Oswald (1967; 1975); Sergeant; Lowber (1869).

31. Para mais informações sobre a produção em Southampton, ver Arnold (1977), e, sobre a produção da região de Portsmouth, ver Fox; Hall (1979). 
um tipo específico de cachimbos longos de alta qualidade, o que teria conferido ainda mais popularidade à região produtora.

Entre os anos de 1670 e 1740, o rapé se tornou difundido também na Inglaterra, hábito importado da França, especialmente nas classes mais altas, afetando o mercado de cachimbos. $\bigcirc$ único centro que cresceu neste momento é Liverpool, possivelmente devido ao papel desempenhado por essa localidade no comércio de escravos e pirataria. Os produtores, então, entre os séculos XVII e XVIII, buscaram produzir outros objetos de cerâmica para manter seu ganho, tais como modeladores de cachos para cabelos ou soleiras. Durante o século XIX, a Revolução Industrial teria dado fôlego para a indústria de cachimbos, mas já na metade daquele século enfrentou forte concorrência com os cachimbos esculpidos no mineral espuma do mar ou silicato hidratado de magnésio (meerschaum), que contém sepiolita, entre outros componentes, e os esculpidos em betouro (briar), uma raiz da pequena árvore também denominada urze-molar.

Em decorrência da competição, a indústria da produção de cachimbos de cerâmica como um todo sofreu reduções drásticas durante o XIX e, até o ano de 1870, a grande maioria dos produtores já havia fechado suas portas. A título de exemplo, a produção na região do porto de Portsmouth cessou completamente em 1932, pela perda de mercado frente aos já mencionados cachimbos de briar e de meerschaum e já também de cigarros. Ainda há hoje na Inglaterra alguma produção, porém pequena. Segundo Walker, ${ }^{32}$ a única empresa sobrevivente é a John Pollock and Company, de Manchester.

Após esse histórico dos principais centros ingleses de produção de cachimbos de caulim, vale mencionar que, além das cidades portuárias de Londres, Liverpool, Portsmouth, Bristol e Southampton, assim como a cidade de Broseley, também as regiões de York e Hull ao norte da Inglaterra foram importantes na produção de cachimbos brancos (Oswald, 1967; Higgins, 2009). Outras localidades produtoras na Inglaterra foram Barnstaple, Bedfordshire, Berkshire, Bodmin, Buckinghamshire, Cheshire, Gateshead, Guernsey, Chester, Cornwall, Cumberland, Exeter, Derbyshire, Devonshire, Dorset, Essex, Gateshead, Gloucestershire, Guernsey, Jersey, Hampshire, Herefordshire, Hertfordshire, Huntingdonshire, Humberside, Leicestershire, Lincolnshire, Manchester, Middlesex, Northamptonshire, Nottingham, Norfolk, Oxford, Oxfordshire, Portchester, Staffordshire, Suffolk, Sussex, Warmwickshire, Westmorland, Wiltshire, Worcestershire, entre outras.

Havia alguma produção de cachimbos de caulim também na Irlanda (com os primeiros produtores datando de c. 1687, nenhum no século XVIII e 23 produtores conhecidos entre 1819 e 1917), na Escócia (indústria forte e exportadora, muito bem estabelecida no início do século XVIII) e no País de Gales lao menos seis produtores entre 1812 e 1850 e indícios anteriores, referentes ao século XVIII.

Essa produção altíssima de cachimbos no Reino Unido foi tanto para consumo interno quanto para exportação lque compreendeu vários pontos na África, 
Ásia, América e Europa, incluindo a península lbérica, o Mediterrâneo e o Báltico). Para se ter um parâmetro temporal da exportação de cachimbos para os atuais EUA, há registro recuado de cachimbos ingleses na Virgínia (Martin's Hundred) em c. 1619-1622. Sugere-se inclusive que os cachimbos teriam sido usados não somente pelos colonos, mas também em trocas com os indígenas nos EUA. Vários produtos, inclusive, eram projetados para mercados específicos, como foi o caso de um fabricante em Bristol ter estilos distintos para a África, a América, a Espanha e a Irlanda - informação esta retirada de uma propaganda datada de 1799. O tipo mais distinto voltado para exportação no XVIII era o cachimbo sem pedúnculo, ou em cotovelo, que não se tornou comum na própria Inglaterra até meados do XIX.33

Na Austrália, foram identificados cachimbos provenientes do Reino Unido e, em áreas portuárias, também da França, Holanda, EUA e Alemanha até c. 1850 e, a partir desse momento, predominantemente da Escócia lem particular do fabricante Thomas White and Co.). A partir do século XIX, essa região passou a ser dominante na exportação internacional de cachimbos, posição até então ocupada por Londres, Bristol e Southampton.

\subsubsection{Holanda}

A produção de cachimbos na Holanda foi igualmente expressiva e também para exportação, desde o século XVII. Cachimbos holandeses são encontrados na Escócia e, em menor quantidade, também na Inglaterra, especialmente associados a áreas portuárias, talvez provenientes da quebra fortuita de cachimbos de marinheiros. ${ }^{34}$ Há registro também da existência de comércio com Portugal e Espanha. Além disso, são encontrados das colônias do Novo Mundo à Austrália, inclusive no Brasil.

Os primeiros produtores de cachimbos na Holanda eram ingleses, dos quais alguns eram soldados, fugidos da Inglaterra em decorrência das restrições postas por James I, e também de proibições religiosas. Para Duco, um fator que atesta essa origem inglesa do fabrico holandês de cachimbos brancos de tabaco é a utilização de palavras e termos ingleses associados à feitura desses itens: kasten, wire, tremmen, glazen, smoeien, zoken, rollen, wrochten, stopper, botter e rodeur. A menção mais antiga é a de dois ingleses em Amsterdã, William Jorreson Boyesman e Thomas Lourens, em 1611 . A indústria teria então se distribuído para outras cidades holandesas, tais como Haarlem, Roterdã, Froningen, Leiden e Gouda. No período que antecede 1620, o fumo ainda era pouco aceito socialmente na Holanda, mas a disseminação do hábito e do ofício foi tal que, em 1665, havia 80 fabricantes; em 1979, 161; em c. 1750, 340.

Centros produtores de importância foram Alkmaar, Amsterdã, Bergenop Zoom, Breda, Delft, Deventer, Dordrecht, Enkhuizen, Gorinchem, Gravenhage (Haia), Groningen, Gouda, Haarlem, Harlingen, Hoorn, Kampen, Leeuwarden, Leiden, Maastricht, Middelburg, Roterdã, Schiedam, Schoonhoven, Tholen, Willinge-Langerak, Zwolle, entre outros. ${ }^{35} \mathrm{Em}$ cerca de 1850, havia várias fábricas
33. Para alguns exemplos de exportação global de cachimbos de caulim, ver Bárcena (2013), Calado; Pimenta; Silva (2003), Gojak; Stuart (1999); Higgins (1995; 2009).

34. Essa possibilidade foi aventada por Higgins (1995).

35. Duco (1987). 
36. A P. J. Van der Want (1749-) ainda produz cachimbos de caulim, em duas fábricas, a Zenith Plateelbakkerij e a Pijpenfabriek (Walker, 1971). de grande porte na Holanda, como as das famílias Goedewaagen e P. J. van der Want, ambas de Gouda. ${ }^{36}$

Embora toda a província Holanda do Sul apresentasse fabricantes do produto, o mais renomado centro produtor de cachimbos de caulim na Holanda como um todo foi Gouda, sobretudo a partir da década de 1640. $O$ fabricante mais antigo de Gouda também era inglês, estabelecido em 1617, Willem Barends (ou William Bearnelts, na possível versão inglesa do nome).

No que tange à qualidade do produto, Gouda produzia três tipos de cachimbos, Bourtange, dois tipos, e Schoonhoven, apenas o tipo mais simples e de pior qualidade. Embora apenas mais adiante neste texto esses tipos serão detalhados, já vale ressaltar que Gouda produzia mais variações de qualidade e os mais refinados, em grande parte, devido à sua corporação de ofício. Uma evidência da reputação de Gouda é a recorrente utilização, nos séculos XVIII e XIX, da impressão do brasão de armas da cidade na peça como um sinal da localidade de sua produção.

A corporação de Gouda foi instituída em 1660, perdurando até 1795. Embora não fosse a mais antiga corporação desse ofício na Holanda, a exemplo da corporação de Gorinchem, instituída em 1656, esta era a mais rígida. Os regulamentos abordavam aspectos como o trabalho infantil la idade mínima para - trabalho era de 18 anos); o tamanho das saggars, limitado para facilitar o empilhamento nos fornos (que por vezes eram usados por vários fabricantes); preços segundo o tipo; entre outros. Além disso, mesmo vendedores em Gouda tinham que trabalhar na produção por dois anos, antes que lhes fosse permitido comercializar o produto.

A popularidade dos cachimbos de Gouda como itens de qualidade foi tão forte que se tornou comum a cópia de marcas de fabricante dessa cidade. Interessa apontar que as imitações do produto de Gouda, muitas vezes, eram malfeitas, em especial nas marcas de fabricante, com letras ou números malformados ou desproporcionais, ou com a adição ou omissão da coroa em relação à marca original. Na primeira metade do século XIX, Gouda ainda influenciava o estilo da produção de cachimbos nacional e internacionalmente, mas, a partir da metade daquele século, a influência de outros países (França, Bélgica e Alemanha), especialmente em termos artísticos, implicou a diminuição do alcance da indústria de Gouda.

Apesar da maior popularidade e qualidade do produto de Gouda, os cachimbos feitos na cidade já mencionada de Gröninger eram produzidos e exportados em maior número, uma vez que, em geral, apresentavam menor qualidade. Além disso, o produto dessa localidade foi menos sensível a flutuações de estilo que em outros locais. Nessa cidade, também produzia-se muitas imitações dos cachimbos de Gouda, com qualidade visivelmente inferior. Outro centro que os imitava era Alphenaanden Rijn, cidade na província da Holanda do Sul.

A produção de cachimbos em Schoonhoven, outro centro digno de menção, começou na primeira metade do XVII, tal como Amsterdã, Gouda e Roterdã, porém, apesar de contínua, deu-se em menor escala. A indústria se tornou 
mais importante até o início do XVIII, com a corporação dos produtores dessa cidade sendo instituída somente em 1767. Os regulamentos regiam apenas questões como a necessidade de marcar iniciais do nome do produtor com a inserção de "van", mas não normatizavam sobre quais seriam as marcas utilizadas. Era permitido que trabalhadores regulares em outros ofícios atuassem como fabricantes de cachimbos durante o inverno, tal como era possível também o trabalho infantil. Duco ${ }^{37}$ sugere que essa mão de obra menos qualificada poderia explicar a baixa qualidade em relação aos produtos de Gouda. Além disso, em decorrência da frouxa regulamentação por parte da corporação em Schoonhoven, várias cópias de marcas de Gouda foram produzidas.

Em 1795, todas as corporações de ofício que regulamentavam a atividade dos fabricantes de cachimbos cessaram. Isso decorreu do declínio da demanda, em razão da competição de outros países e de produtos similares. Contudo, os cachimbos holandeses, em especial os de Gouda, eram, ainda no século XIX, mais caros que os cachimbos ingleses e irlandeses do mesmo período. ${ }^{38}$

\subsubsection{França}

Segundo Faveton, 39 foi durante a Guerra dos Trinta Anos (1618-1648) que os primeiros cachimbos de cerâmica chegaram à França. Em meados do século XVII, produtores ingleses teriam se estabelecido na Normandia, Roven, no bairro Saint-Sever, fabricando itens de baixa qualidade e baratos. Na região de Flandres, produziam-se cachimbos à imitação dos de Gouda, ainda em meados do século XVII, enquanto em Dunquerque, cidade portuária no norte da França, onde havia vários cabarés (guinguettes), produziam-se cachimbos de fornilho pequeno.

A partir de meados do século XVII, surgiram vários centros de fabricação de cachimbos de argila, em vários locais na França: na Bretanha, em Rennes (fábrica Crétal Gallard); na Ilha de França, em Montereau (fábrica Dutel-Gisclon); na Normandia, em Dieppe; nas Ardenas, em Charleville; em Languedoc, em SaintQuentin-La-Poterie. Durante a segunda metade do XVIII, no norte da França foram abertos vários importantes centros produtores de cachimbos (nas cidades de SaintOmer, Givet e Onnaing). À medida que o rapé se democratizou, os produtores de cachimbos passaram a produzir itens mais luxuosos como inovação, para atingir as camadas mais abastadas. Além da existência de cachimbos em outros materiais, como a madeira, marfim, metal e até mesmo vidro, os fabricantes de cachimbos de cerâmica também inovaram nos modelos. Os estilos passam a referir-se à literatura, história, bíblia e mitologia, ainda mantendo motivos florais e faunísticos. Outros temas mais específicos eram trens, automóveis, torre Eiffel e temas orientais. São especialmente conhecidos os cachimbos figurando personalidades, os chamados french clays. A maior parte dos french clays eram fornilhos moldados com piteira de madeira. O tipo mais comum desses cachimbos é o Jacó, com turbante na cabeça. Um detalhe comum nesses cachimbos é o uso de esmalte em cores no rosto das figuras.
37. Duco (1980b).

38. Para mais informações sobre a produção de cachimbos holandesa, ver Duco (1980a; 1980b; 1993), Meulen (2003), Oosteveen (2001; 2009; 2011; 2012); Oswald (1967).

39. Faveton (1988). 
Os mais famosos produtores franceses dataram da segunda metade do século XVIII à primeira metade do XX, localizados especialmente no norte do país. Essa região teve grande papel na notoriedade que ganhou o cachimbo francês no século XIX, produzindo largamente também para exportação.

A primeira fábrica de tabaco foi fundada em Saint-Omer por volta de 1660 e, em 1789, já havia 28. Essa alta produção na cidade promoveu a instalação de fabricantes de cachimbos. No início do século XVIII, a primeira fábrica de cachimbos foi fundada em Saint-Omer, com forno próprio, nas dependências do Hospital Geral. Quando este fechou em 1794, a fábrica também cessou suas atividades. Duas fábricas de peso foram então fundadas na cidade, a de Thomas Fiolet, em 1765, e a de Duméril Constant, em 1845. Junto com outros fabricantes do país, como Bonnaud, de Marselha, Gambier e Blanc-Garin de Givet, ou Job Clerc de Saint-Quentin-la-Poterie, estão entre os maiores fabricantes de cachimbos da França, entre os séculos XVIII e XIX.

Os produtos da fábrica de Thomas Fiolet, aberta em 1765, eram reconhecidamente de boa qualidade, com polimento incomum se comparados aos ingleses, comumente exibindo a inscrição do nome da fábrica na haste. Lovis Maximilien Fiolet, neto de Thomas Fiolet, assumiu o negócio em 1834, quando o produto recebe a inscrição "L. Fiolet" ou "LF" em várias peças. Em 1851, a exportação para a Inglaterra foi intensificada, com a presença continuada de agentes comerciais em Londres, situação que perdurou até o início do século XX. A Fiolet, iá no século XIX, empregava mais de 700 trabalhadores, produzindo para o mercado interno e externo. Contudo, com a competição trazida pelo charuto e pelo cigarro, mesmo com a diversificação da produção de cachimbos, ela fechou em 1921.

Já a fábrica Duméril, menor que a Fiolet, empregava cerca de 300 a 400 trabalhadores no século XIX, produzindo aproximadamente a metade daquela. Emile Charles Constante (1833-1899), o filho do fundador, sucede o pai, associando-se a Emile Bouveur, de modo que a fábrica passa a ser referida por vezes como Duméril-Bouveur e os cachimbos podem a partir de então receber a inscrição "Duméril Bouveur St. Omer". Duméril comercializou para toda a França, nas colônias francesas, Bélgica, Piemonte, Espanha, África, Inglaterra, Austrália, América (incluindo vastas exportações para os EUA). Como a Fiolet e tantas outras na Europa, a fábrica fecha, em 1886, apenas 41 anos após a sua abertura, em decorrência da concorrência de cigarros, charutos e cachimbo de madeira.

Além das fábricas Fiolet e Duméril, a fábrica Gambier, na cidade nortenha de Givet, também foi de grande importância na produção francesa de cachimbos de caulim, com produtos de qualidade comparável à da fábrica Fiolet. Ela foi fundada por Jean Gambier em 1780. Chegou a produzir, em 1827, uma média de 6500 cachimbos por dia. Com loja também situada em Paris, a fábrica foi muito conhecida por seus fornilhos decorados com fitomorfos, antropomorfos, cabeças de negro, personagens da mitologia, políticos, artistas, zoomorfos /de aves a leões e elefantes), todos em muitas variedades e tamanhos, bastante rebuscados e em cores. Gambier foi notória na produção do cachimbo de Jacó 
Uacob) utilizando-se do slogan: Eu sou o verdadeiro Jacó, o belo Jacó. Foi comprada por Veuve Hasslaver em 1835, que acertou parceria com Louis Fiolet e, posteriormente, duas outras fábricas, também em Givet, a Blanc Garin \& Guyot, e em Lyon, a Noël Frères, que remonta a 1808.40 Após o declínio da produção de cachimbos de argila, atualmente há apenas uma fábrica aberta na França, a Gerard Prungnarud, instalada em Saint-Quentin-la-Poterie. ${ }^{41}$ Para alguns exemplos de cachimbos franceses.

\subsubsection{Alemanha}

A região produtora de cachimbos de caulim mais importante na Alemanha foi a região de Westerwald, no oeste do país. A produção de cachimbos na Bavária remonta ao século XVII, mas era menos organizada, sem associação de produtores e com fabricação concomitante com outras peças em cerâmica. Em Westerwald, ao final do século XVIII, além de produtos mais grosseiros, foram produzidos também cachimbos refinados, que rivalizaram com os produtos de Gouda, para além do alcance regional. Foram encontradas referências ainda para as seguintes regiões: Zittau, Bernstadt, Wittenberg e Dresden; Berlim; Görlitz e Bernstadt; Pirna, Kirchgasse; Freiburg; Breisgau; Bavária; Bohemia; Bremen, norte da Alemanha. Hamburgo é citado como um centro que produzia imitações dos cachimbos de Gouda. ${ }^{42}$

Segundo Meher, grande quantidade dos cachimbos usados na Alemanha eram holandeses (Gouda) e os fabricantes alemães de cachimbos também tiveram grande influência holandesa. Contudo, a arqueóloga defende que, ainda assim, os cachimbos alemães desenvolveram suas próprias características e técnicas. Ela aponta que os cachimbos alemães produzidos na Bavária não apresentam a linearidade cronológica da mesma forma que ocorre com os de Gouda. Os fornilhos dos cachimbos da Bavária também cresceram. Porém, a partir do momento em que se passou a produzir fornilhos grandes, os menores não deixaram de ser também produzidos. Isso significa que os fornilhos menores não necessariamente são anteriores aos maiores. Desse modo, a sequência de tipos a ser aplicada para análise desses cachimbos deverá ser particular e não linear, de acordo com marcas de fabricante, por exemplo. Além disso, a única referência encontrada nesta revisão para cachimbos de caulim produzidos por meio de torno, não apenas o moldado, foi na Alemanha. ${ }^{43}$

poucas menções ao caulim

2.2.5. Digressão: produção de cachimbos nos EUA e as

Vale mencionar, ainda que brevemente, o caso dos atuais EUA. Nessa colônia, havia importação de cachimbos ingleses de cerâmica branca em grande quantidade e, em menor escala, provenientes da Holanda e da França. Há
40. Para mais informações sobre a fábrica Gambier, ver $<$ http://www.gambierpipes. $\mathrm{com} / \mathrm{fr} / \mathrm{histoire-de-gam-}$ bier/>. Acesso em: 14 ago. 2016 .

41. Para mais informações sobre a produção francesa de cachimbos de caulim, ver Hammond (1987), Humphrey (1969), Lévêque (2014).

42. Duco (1993).

43. Para mais informações sobre a produção alemã de cachimbos de caulim, ver Mehler (2009a; 2009b), Kluting-Altmann; Mehler (2007), Kluting-Altmann (2013), Teichner (1998). 
44. Bradley; DeAngelo (1981), Cotter (1957), Higgins $(1995 ; 2009)$.

45.Reckner; Dallal (2000).

46. Luckenbach (s.d), Luckenbach; Kiser (2006).

47. A bibliografia consultada parece indicar maior utilização de argilas vermelhas que brancas na produção estadunidense. Isso é reforçado pelo dado já citado neste artigo da descoberta tardia em 1880 de jazidas de ball clay nos EUA. É possível ainda que a mencionada importação de ball clay proveniente de Devonshire, Inglaterra (Sudbury; Gerth, 2011, p. 20), tenha suprido o uso em cachimbos como em outros produtos cerâmicos, ou ainda que eram as china clays, identificadas nos EUA ainda no século XVIII, que eram misturadas a argilas vermelhas (Sudbury; Gerth, 2011). Contudo, referências sobre o tópico não foram encontradas no âmbito desta revisão.

48. Sudbury; Gerth (2011, p. 14-15).

49. Os cachimbos de presidentes estadunidenses foram também produzidos na Europa para exportação, referidos na literatura como President Pipes, estes feitos em terracota, onde figuram rostos dos presidentes americanos, como Lincoln e George Washington, no fornilho. Estes foram produzidos em especial pela Alemanha. Ver Hume (1985), Pfeiffer; Gartley; Sudbury (2006).

50. Para mais informações sobre a produção e o consumo de cachimbos estadunidenses, ver Bell (2004), Hume (1985), Luckenbach (s.d), Luckenbach; Kiser (2006), Luckenbach; Sharpe (2007), Monroe; Mallios (2004), Monroe; Mallios; Emmett (2004), Murphy (1978), Pfeiffer; Gartley; Su- ocorrências arqueológicas desses desde o início do século XVII, a exemplo dos sítios Martin's Hundred (c. 1619-1622) e Jamestown, ambos no estado da Virgínia. A presença de cachimbos ingleses de caulim nos EUA indica importação significativa até meados do XVIII e sua presença não se limitava aos sítios dos colonos, mas também aparece em sítios de contato. ${ }^{44}$ Havia importação de cachimbos produzidos na Europa especialmente para o mercado estadunidense, como o tipo com decoração acanalada nos fornilhos, os cachimbos T.D. e os adornados com 13 estrelas, recorrentes no século XVIII. $\bigcirc$ uso de cachimbos de caulim europeus também ocorreu no século XIX. ${ }^{45}$

Apesar da importação do produto europeu, a colônia inglesa chegou a produzir cachimbos utilizando-se de argila branca e do molde importado. Entre os produtores do século XVII na região, destaca-se o inglês Emanuel Drue, que se estabeleceu em Swan Cove, Maryland, entre as décadas de 1650 e 1660, produzindo cachimbos de dois tipos, um deles seguindo o estilo indígena Chesapeake e outro utilizando o molde europeu. Este último era decorado tanto no estilo inglês da época (anel serrilhado na borda), quanto com motivos indígenas aplicados com carimbo após sua forma ser feita no molde inglês. ${ }^{46} \mathrm{~A}$ argila usada variava do branco ${ }^{47}$ ao vermelho, com maior frequência do vermelho. Hume adiciona que, por volta de meados do século XVII, algumas cópias de cachimbos ingleses foram produzidas na Virgínia e na Nova Inglaterra.

Contudo, deve-se notar que o cachimbo de argila vermelha constituía a produção mais recorrente e uma considerável produção interna. Sobre a fabricação de cachimbos nos EUA em termos quantitativos, tem-se um total de 19 produtores entre 1776 e 1840, com a possibilidade de muitos outros não documentados, número que cresce durante o século XIX. ${ }^{48}$ Em argilas vermelhas de produção nos atuais EUA, destacam-se os cachimbos de presidentes, ${ }^{49}$ os Shaker pipes e os da região de Chesapeake, que receberam mais atenção e pesquisa. A maior parte destes eram cachimbos curtos (cuja haste é vegetal e de encaixe), de terracota e os moldes eram mais frequentemente distintos daqueles utilizados na Europa. Alguns cachimbos foram produzidos também com misturas aparentes de argilas distintas, criando um efeito semelhante à ágata. Inclusive, grandes quantidades de cachimbos feitos localmente são encontradas na Virgínia do segundo quartel ao final do XVII, incluindo os já mencionados em efeito ágata, alguns com serrilhados e carimbos. ${ }^{50}$

\section{Técnicas de fabricação de cachimbos de caulim na Europa}

As técnicas de fabricação dos cachimbos de argila branca variaram relativamente pouco ao longo dos anos e de acordo com o centro produtor. Os processos inglês e holandês eram semelhantes. Iniciavam-se pelo processamento da argila (quebra, seguida da umidificação, para remover impurezas e ar), que envolve grande energia e tempo, até que a matéria esteja apta para ser manuseada. Esse preparo era feito manualmente, com pilão, ou com o auxílio de máquina. Uma 
vez removidas as impurezas, a água era escoada. A receita exata da pasta variava, como já dito, conforme centros produtores, disponibilidade da argila, entre outros fatores. Por exemplo, uma receita de dado fabricante em Gouda consistia em duas cestas de argila inglesa e seis de argila alemã ${ }^{51}$ A argila, após preparada, era separada manualmente em porções pequenas para fazer a pré-forma. Esta era o rascunho do cachimbo, assemelhado a um rolete. $\bigcirc$ fio de ferro era então introduzido onde seria a haste, para formar o orifício de saída da fumaça. Em seguida, essa forma era colocada no molde previamente untado, geralmente de duas partes, seguido da perfuração do fornilho (por instrumento manual ou máquina). $\bigcirc$ excesso de argila era cortado das bordas do molde, com um fio ou outro instrumento. Após isso feito, o cachimbo era retirado do molde. A peça então recebia quaisquer elementos adicionais decorativos ou identificadores, carimbados (carimbo de madeira), incisos ou serrilhados (botões serrilhados), e eram colocados em uma bandeja para secar antes da queima. Durante a secagem dos cachimbos, o fio permanecia no orifício da haste, para evitar distorções da argila durante a sua retração. Nos cachimbos longos, esse fio era removido antes de totalmente seco o cachimbo, e sua haste era levemente entortada, dando a forma desejada. Nesse momento a queima era feita, com ou sem o uso das saggars.

Vale já mencionar que o fio usado na feitura do furo da haste afina com o tempo, à medida que a tecnologia no fabrico do próprio fio avança. Esse dado é fundamental na datação dos cachimbos, uma vez que o ritmo da diminuição do furo segue um padrão, para cachimbos ingleses, como será descrito mais adiante. É importante lembrar também que o furo menor contribui para que a fumaça chegue menos quente ao fumante.

A bibliografia em geral sobre a técnica de fabrico de cachimbos considera sua feitura por meio de molde de duas partes, desenvolvido na Inglaterra antes de 1600. Essa técnica foi utilizada amplamente na Inglaterra e na Holanda. Havia, contudo, moldes de mais partes, para decorações mais complexas, como o cachimbo de Jonas, que era feito com molde de quatro partes.

Os primeiros moldes eram feitos de latão ou madeira e, já por volta de 1750, de ferro fundido. Na Holanda do XVII, moldes de bronze foram bastante empregados. Em Gouda, normalmente os moldes eram feitos por um ferreiro e um gravador fazia as decorações e inscrições na peça. A partir do século XX, uma técnica utilizando moldes de gesso lque poderiam ser usados apenas aproximadamente 30 vezes, devido ao desgaste) foi desenvolvida em Gouda, possibilitando a criação rápida de novos estilos. ${ }^{52}$ Apesar da menção de Oswald sobre a ausência de moldes de bronze na Inglaterra, segundo Walker estes foram usados até o final do século XVIII, sendo que no início do século seguinte, moldes de ferro foram introduzidos. ${ }^{53}$ Como a argila é abrasiva, os moldes se desgastavam com o tempo, de modo que as hastes do cachimbo poderiam apresentar diâmetros maiores e a decoração, menos definição. Na França, moldes de gesso também foram utilizados.

Na Inglaterra, os moldes eram adquiridos de um centro distribuidor. Contudo, ocorriam marcas locais, como inscrições de produtores, estabelecimentos dbury (2006), Sharpe; Luckenbach; Kille (2000).

51. Duco (1980a).

52. Duco (1984).

53. Oswald (1975), Walker (1971). 
54. Price (1985).

55. Walker (1971). ou eventos, especialmente no século XIX. Por exemplo, uma proeminente família produtora eram os Leigh, em Portsmouth, que produziram entre 1840-1930, e é possivel ver esse nome reproduzido em cachimbos. Price sugere, a partir de um estudo de inventários ingleses, que os fabricantes mais estabelecidos utilizavam cerca de 10 moldes por vez. ${ }^{54}$ Já os carimbos que deixavam a marca dos fabricantes na peça eram geralmente de madeira e poucos foram encontrados arqueologicamente.

Uma máquina inventada na Inglaterra no século XVII (provavelmente entre as décadas de 1610 e 1640) teria revolucionado a feitura dos cachimbos feitos por molde de duas peças, com implicações também na decoração, a saber, a prensa manual de alavanca (press gin ou gin-press). Tratava-se de uma mesa de trabalho, cuja alavanca nela fixada continha na sua ponta a forma negativa do vão do fornilho. Ao ser puxada, a alavanca formava o vão do fornilho com um movimento simples, de cima para baixo. Ressalta-se que, dado o movimento feito pela alavanca, quando marcas são visíveis na face interna do fornilho, elas são na direção vertical em relação ao corte da borda. A forma da prensa tornava difícil (mas não impossível) de se fazer fornilhos em ângulo agudo em relação à haste. Isso pode ter influenciado a forma dos cachimbos após 1700 e introdução da máquina (que se populariza mais na segunda metade do XVIIII).

Enquanto os franceses utilizavam um mecanismo similar à prensa inglesa (gin-press), é importante apontar que os fabricantes holandeses não utilizavam essa prensa, mas uma perfuratriz manual, com movimento em rosca. Assim, quando a feitura do vão do fornilho se dava dessa maneira e deixava marcas, essas tendem à direção horizontal frente à borda do fornilho. Walker sugere que o desenvolvimento particular da perfuratriz holandesa pode ter relação direta com as finas paredes dos fornilhos de cachimbos holandeses e qualidade superior pela qual eram famosos. ${ }^{55}$

Entre marcas mais pessoais nos cachimbos feitos por molde de duas partes estão as de dedos, impressas antes da queima das peças, por exemplo. Nas costuras de molde, é possível observar falhas no encaixe das suas partes, especialmente quando estes carregam o negativo de uma decoração intrincada. O molde de duas partes também pode produzir uma linha protuberante após a prensa, que poderá ser observada em peças se a limpeza dos excessos de argila for parca. Nos cachimbos de melhor qualidade, procurava-se remover essas sobras da argila na costura do molde. Considerando esse ponto, outra diferença entre o fabrico holandês e inglês está no acabamento: na Inglaterra, a limpeza das sobras era comumente feita após a secagem, enquanto na Holanda alguma limpeza já era feita logo após a retirada do molde. Sobre o acabamento de superfície, após toda essa preparação da forma, o cachimbo poderia ser lustrado antes da secagem, com o uso dos dedos, mas o polimento, de fato, quando ocorria, era feito após a queima.

Ou as saggars ou os muffles costumavam ser utilizados para acomodar os cachimbos durante a queima. Para Oswald, as saggars só foram introduzidas na Inglaterra no século XIX. Antes disso, cadinhos ou muffles, recipientes refratários feitos de fragmentos de hastes, teriam sido utilizados. Contudo, Peacey menciona 
evidências do século XVII ao XX para as saggars. Ainda, o autor sugere a data de 1612 para a introdução dos muffles na Inglaterra, até o século XX. ${ }^{56}$

Quanto à queima, Oswald menciona a existência de três tipos de fornos ${ }^{57}$ :

1. Fornos ingleses pequenos, circulares, com diâmetro de cerca de 1,40 metro. Os cachimbos eram acomodados em cadinhos ou muffles;

2. Fornos ingleses grandes em forma quadrada, medindo 3,80 metros de diâmetro. Uso de saggars;

3. Fornos holandeses grandes arredondados, medindo 5 metros de diâmetro. Uso de saggars.

Apesar da menção ao fato de o tipo 1 ocorrer em Portsmouth no século XVII, e no XIX em Boston, Stamford e Lewes, não é oferecida uma cronologia evolutiva desses fornos.

Quanto ao disposto sobre fornos holandeses, Duco aponta que até o século XIX os fabricantes de cachimbo holandeses utilizavam fornos de ceramistas, pagando pelo seu uso, mais barato do que construir fornos próprios. ${ }^{58}$ Esses ceramistas aproveitavam as fornadas para seus próprios produtos, incluindo peças em argilas vermelhas. Não obstante, alguns fabricantes de cachimbos chegaram a construir fornos, após concedida a permissão de construí-los, em 1747. Segundo Duco, eram fornos circulares, o que coincide com a informação oferecida por Oswald, sem chaminé, mas três aberturas no teto.

Carvão vegetal (charcoal) ou madeira eram usados nos primeiros fornos, mas foram substituídos por fornos alimentados a carvão mineral (coal) ou coque (coke). A mudança teria acontecido entre os séculos XVII e XVIII.

A temperatura de queima era em torno de $940-975^{\circ} \mathrm{C}$ na Inglaterra. Quanto mais alta, mais resistente seria o cachimbo resultante, porém, ele também seria menos poroso e, consequentemente, a fumaça seria mais quente. $\bigcirc$ processo da queima duraria entre 50 e 60 horas.

$\bigcirc$ polimento e/ou o tratamento da boquilha visando evitar que os lábios grudassem no cachimbo era feito após essa primeira queima das peças. Na Holanda, foi frequente o mergulho em mistura de sabão com cera e colocado em água fervente por meia hora, para dar brilho à peça como um todo, e torná-la menos porosa (no caso dos cachimbos mais finos, denominados porceleiine, como será discutido mais adiante). $\bigcirc$ cachimbo podia, ainda, ser polido com um pano. Em um polimento mais requintado, usado frequentemente em Gouda, após o mergulho anteriormente descrito, passava-se um "lápis" cônico de ágata no cachimbo quando a argila se encontrava em ponto de couro. ${ }^{59}$ A técnica do mergulho seria anterior à técnica da ágata.

Segundo Walker, na Inglaterra, não foi muito comum o polimento, exceto no período entre 1650-1700, quando o método da ágata foi um pouco mais utilizado. Já Higgins faz menção ao uso infrequente de polimento em cachimbos do século XVII. Por outro lado, Oswald faz uma breve menção a polimento. Segundo o arqueólogo, o polimento foi feito na Inglaterra durante todo o período de produção, de modo que ele não teria valor cronológico. Além disso, são encontradas boquilhas
56. Oswald (1975), Peacey (1996).

57. Para detalhes de fornos ingleses de cachimbos de caulim, Peacey (1996). Ver também Oswald (1975).

58. Duco (1984).

59. O ponto de couro se dá quando a argila apresenta consistência similar à do couro. Ela está, então, seca o suficiente para não se retrair mais, podendo ser manipulada sem se deformar ou se quebrar, mas ainda está passível de receber acabamento, como incisões ou alisamentos. Ver Shepard (1985). 
60.Sobre essa questão, ver Higgins (2009), Jackson; Beckey; Baker (1991), Oswald (1975), Walker (1971).

61. Para mais aprofundamento sobre a técnica mais comum de fabrico de cachimbos de caulim na Europa, ver especialmetne Duco (1980a; 1980 b), Higgins (2009), Oswald (1975).

62. Kluttig-Altmann (2013).

63. Fox (2002), Moloney (2013), Pierce (2007), Sudbury; Gerth (2011). esmaltadas (tratamento que requer uma segunda queima) a partir do século XVIII. Por exemplo, em um sítio de produção de cachimbos em Bristol, Inglaterra, em um depósito de descarte de material do XIX, foi encontrado um cadinho com sobras de esmalte verde e fragmentos de haste, que teria sido usado nessa etapa de esmaltar a peça. Nota-se que a informação sobre polimento na Inglaterra é fragmentária e contraditória em alguns pontos. Porém, pode-se extrair que nesses cachimbos o polimento poderia ocorrer em todos os momentos da produção, incluindo o método da ágata, e que, a partir do XVIII, as boquilhas poderiam ser esmaltadas. .0

A técnica até agora descrita, ${ }^{61}$ da feitura de cachimbos de caulim por meio de moldagem, é geralmente apresentada como ubíqua na Europa. Contudo, há uma referência, relativamente recente, que apresenta duas técnicas distintas adicionais, produzidas em Görlitz, Bavária e Lusatia Superior, na Alemanha. A primeira dessas técnicas é a feitura do fornilho em torno, seguida pela montagem de uma haste feita separadamente. A segunda é a feitura completamente manual do cachimbo, em uma única peça. Em ambas as técnicas, a haste é dobrada posteriormente no ângulo desejado. É importante lembrar que o torno deixa marcas também características, na porção interna do fornilho, tal como potes feitos em torno. Já os cachimbos completamente moldados deixam marcas mais diversas, relacionadas ao manuseio da argila antes da queima. Dada a sua feitura mais artesanal que $\circ$ molde, os cachimbos assim produzidos podem apresentar marcas distintas de dedos. A decoração desses cachimbos inclui decorações manuais, como o serrilhado (milling ou rouletting) aplicado não somente na borda do fornilho, e não inclui polimento. Essa técnica independente de se fazer cachimbos de caulim sugere, para KluttigAltmann, que a ideia do fumo de tabaco se espalhou mais rapidamente pela Europa do que a técnica anglo-holandesa de manufatura dos cachimbos. ${ }^{62}$

\section{1. Preço dos cachimbos}

Os cachimbos são normalmente descritos como itens muito baratos, o que se relaciona diretamente com o fato de serem altamente descartáveis. Segundo Sudbury e Gerth, o tempo entre a manufatura de um cachimbo, sua importação, uso e descarte ocorria em tempo médio menor que dois anos. Em decorrência desse caráter descartável do cachimbo, lembra-se que sua produção foi intensa lestima-se que, no século XVIII, então já com o auxílio da gin-press, um fabricante habilidoso conseguiria produzir cerca de 500 cachimbos de haste longa por dia). Nesse sentido, é interessante apontar as enormes quantidades de cachimbos listados em inventários de espólios de indivíduos falecidos em Port Royal, Jamaica (de 258 a 11.520 cachimbos), de modo que o estoque de admiráveis quantidades atesta o seu intenso consumo. Contudo, como aponta Moloney, apesar de serem itens baratos, havia uma gradação de preços, conforme a sua qualidade. Por exemplo, seu preço poderia variar de acordo com comprimento da haste e presença de esmalte. Ainda, Pierce aponta um dado interessante para o caso da exportação: os preços dos cachimbos variavam conforme o mercado para o qual eram destinados. ${ }^{63}$ 
Para pedidos menores e para o mercado interno inglês, eram frequentemente vendidos por lote (ou gross) de 192 cachimbos. Algumas poucas referências bibliográficas sobre o tópico foram encontradas no âmbito desta revisão. Contudo, considerando a dificuldade tanto na disponibilidade de valores absolutos para preços, como da interpretação desses dados, Fox aponta para o valor médio de 1 xelim ${ }^{64}$ por lote, no século XVII, de cachimbos de Bristol.

Outra referência estima que os valores em Bristol, em 1799, variavam em torno de 2 a 5 xelins pelo lote, considerando tamanho, tipo e qualidade, com o mais simples e de tamanho "comum" custando 1 xelim (cujo símbolo é "s") e 8 pence (cujo símbolo é " $d$ "), 5 xelins os esmaltados. Os mais caros seriam os longos aldermans (século XVIII) ou os ainda mais longos churchwardens (século XIX). Barca aponta para os valores de 4 xelins por lote para cachimbos ingleses de haste longa, aproximadamente três vezes mais caros, em meados do XVIII. ${ }^{65}$ Fox e Hall aludem a referência também do XIX para o valor de 8 pence por lote. Há que se considerar também as relações de oferta e demanda do produto, conforme Gojak e Stuart apresentam para o caso da Austrália. $\bigcirc$ produtor australiano, em função de competição com produtos ingleses e holandeses, na década de 1840, barateou seu produto de 5 para 4 xelins por lote, depois para 2 xelins e 6 pence. ${ }^{66}$

A tabela a seguir oferece uma base comparativa dos custos dos lotes de cachimbos, face a um produto basilar na alimentação popular, o pão. As referências consultadas ${ }^{67}$ apontam que, ao longo do tempo, o preço do pão variou bastante, em parte em função das colheitas, atingindo um pico durante as Guerras Napoleônicas. Contudo, de modo geral, pode-se estimar que, no século XVII, um lote de cachimbos custava algo próximo do valor de dois ou três pães. No século seguinte, um lote custava cerca de três pães, sendo que os cachimbos longos, seis. No início do século XIX, em decorrência da queda da demanda por cachimbos de caulim e das guerras napoleônicas, os custos se aproximam da escala de 1:1.
64. 1 xelim $=12$ pence $(d)$; 20 xelins em 1 libra.

65. Barca (2012), Higgins (1995), Pierce (2007).

66. Gojak; Stuart (1999).

67. Clark (2011), Hearfield (2009), MacFarlane; Mortimer-Lee (1994).

68. Ressalta-se que não foram identificadas referências bibliográficas para preços absolutos de cachimbos holandeses.

Tabela 1: Custo comparado de cachimbos e pães ${ }^{68}$

\begin{tabular}{|c|c|c|c|c|c|}
\hline \multicolumn{3}{|c|}{$\begin{array}{l}\text { PREÇO DO LOTE DE CACHIMBOS (192 } \\
\text { unidades no mercado interno) }\end{array}$} & \multicolumn{3}{|c|}{ PREÇO DO PÃO } \\
\hline DATA, LOCAL & $\begin{array}{l}\text { PRECCO DO } \\
\text { LOTE }\end{array}$ & FONTE & DATA, LOCAL & $\begin{array}{l}\text { PREÇO DO } \\
\text { PÃO (4 lb.) }\end{array}$ & FONTE \\
\hline \multirow{4}{*}{ Séc. XVII, Bristol } & \multirow{4}{*}{1 xelim } & \multirow{4}{*}{ Fox, 2002} & 1620, Londres & $4 d$ & Hearfield, 2009 \\
\hline & & & Década de 1620, Inglaterra & $4,7 d$ & Clark, 2011 \\
\hline & & & 1694, Londres & $5,6 \mathrm{~d}$ & $\begin{array}{c}\text { MacFarlane e } \\
\text { Mortimer-Lee, } 1994 \\
\end{array}$ \\
\hline & & & Década de 1690, Inglaterra & $5,8 d$ & Clark, 2011 \\
\hline
\end{tabular}




\begin{tabular}{|c|c|c|c|c|c|}
\hline \multicolumn{3}{|c|}{$\begin{array}{l}\text { PRECCO DO LOTE DE CACHIMBOS (192 } \\
\text { unidades no mercado interno) }\end{array}$} & \multicolumn{3}{|c|}{ PREÇO DO PÃO } \\
\hline DATA, LOCAL & $\begin{array}{l}\text { PRECCO DO } \\
\text { LOTE }\end{array}$ & FONTE & DATA, LOCAL & $\begin{array}{l}\text { PREÇO DO } \\
\text { PÃO (4 lb.) }\end{array}$ & FONTE \\
\hline \multirow{3}{*}{$\begin{array}{l}\text { Meados do } \\
X V I I I, \text { Inglaterra }\end{array}$} & \multirow{3}{*}{$\begin{array}{c}4 \text { xelins } \\
\text { (cachimbos } \\
\text { longos) }\end{array}$} & \multirow{3}{*}{$\begin{array}{l}\text { Barca, } \\
2012\end{array}$} & 1754, Londres & $4 d$ & Hearfield, 2009 \\
\hline & & & 1756, Londres & $7 d$ & Hearfield, 2009 \\
\hline & & & Década de 1750, Inglaterra & $5,1 d$ & Clark, 2011 \\
\hline 1799, Bristol & 2 a 5 xelins & $\begin{array}{l}\text { Pierce, } \\
2007\end{array}$ & Década de 1790, Inglaterra & $8,2 d$ & Clark, 2011 \\
\hline \multirow{3}{*}{ XIX, Portsmouth } & \multirow{3}{*}{$8 d$} & \multirow{3}{*}{$\begin{array}{c}\text { Fox e Hall: } \\
1979\end{array}$} & $\begin{array}{c}\text { 1803-1815 (Guerras Napoleônicas), } \\
\text { Londres }\end{array}$ & 1xelim e 5d & $\begin{array}{c}\text { MacFarlane e } \\
\text { Mortimer-Lee, } 1994\end{array}$ \\
\hline & & & Década de 1800, Inglaterra & 1 xelim & Clark, 2011 \\
\hline & & & Década de 1810, Inglaterra & 1 xelim e $1 \mathrm{~d}$ & Clark, 2011 \\
\hline
\end{tabular}

69. A queima dita sanduíche ocorre quando a cerâmica é oxidada nas superfícies e reduzida no seu interior. Isso pode se dar em função de uma queima em ambiente predominantemente redutor, seguida pela introdução de oxigênio na etapa final do processo, mas que oxida apenas parcialmente o material, não atingindo o seu interior. $\mathrm{O}$ aspecto resultante é um núcleo cinza e superfície clara.

70. Dallal (s.d.), Wacke (2014).
Além dos preços absolutos dos cachimbos, importa também discutir indicadores de qualidade da peça, o que se torna relevante nesta seção do texto, considerando que os mais bem produzidos eram também os mais caros.

Elementos que afetam o preço dos cachimbos incluem o polimento e acabamento. Essas características são difíceis de identificar em coleções arqueológicas, fragmentárias por natureza. Um indicador de mais fácil visualização em peças arqueológicas, no caso dos cachimbos holandeses, é a letra "S", que indica o tipo de menor qualidade, ou "slegte" (o mais simples dos três tipos de qualidade de cachimbos lá produzidos), marca usada na lateral do pedúnculo a partir de 1740. Um ponto ressaltado em um ou ambos os lados do pedúnculo pode ter sido também uma marca de controle de qualidade. Outro indicador é a coloração. Pontos pretos ou manchas de cores distintas na superfície indicam pior qualidade Ineste caso deve-se ter em mente e eliminar a possibilidade de queimas ou manchas pós-deposicionais). Outro indicador é a presença de inclusões ou bolhas, visíveis a olho nu na quebra, o que indica pior qualidade. Além disso, são indicadores de qualidade a riqueza de detalhes da decoração moldada e a precisão na aplicação de carimbos e serrilhados. Por fim, a queima que chega a altas temperaturas produz cachimbos de melhor qualidade, mais duros e menos porosos. Wacke também discute uma possível relação direta entre queima sanduíche ${ }^{69}$ e a qualidade do cachimbo, tendo realizado lâminas petrográficas de algumas amostras para avaliar as características da pasta. Ela concluiu que essa característica não tem relação com a qualidade do cachimbo (posto que características da argila se comportam uniformemente), mas também sugere que seriam erros de produção. ${ }^{70}$

Assim, os cachimbos de melhor qualidade, de modo geral, apresentam: tratamento de superfície; polimento; cor regular; decoração (quando presente) 
regular, simétrica e detalhada; a haste é circular; o furo da haste é circular; a argila não apresenta inclusões ou bolhas visíveis a olho nu; e queima a altas temperaturas, se feitos a partir do século XVIII. Já na outra extremidade do espectro, cachimbos de qualidade inferior poderão apresentar: cor irregular; tratamento pouco cuidadoso da superfície; decorações menos nítidas e irregulares; haste oval, mesmo na boquilha; furo da haste oval; e queima a temperaturas menos altas, mesmo no século XVIII. Contudo, é necessário o uso de cautela, devendo-se distinguir imperfeições da produção em massa, da má qualidade de coleções específicas inteiras.

Há produtores conhecidos pela qualidade dos seus produtos, sendo, portanto, mais caros. Este é o caso, por exemplo, dos cachimbos produzidos na região de Gouda, na Holanda, ou em Broseley, na Inglaterra. Também ressalta-se que, de modo geral, os cachimbos holandeses detinham melhor reputação que os ingleses e geralmente se consideram esses os mais caros.

\section{Histórico dos métodos de análise dos cachimbos de caulim}

Os cachimbos europeus de cerâmica branca estão presentes em coleções provenientes de sítios arqueológicos dos últimos 400 anos, tanto na Europa quanto nas colônias, por meio de importações. Em estudos arqueológicos, de maneira similar às faianças finas, esses cachimbos podem funcionar como excelentes guias para datar e sequenciar camadas e sítios arqueológicos. Isso porque as transformações que ocorreram nas dimensões e formas de suas partes (haste, cotovelo/pedúnculo e fornilho) são datáveis, tal como o são várias marcas de fabricantes. Além disso, em menor medida, os padrões decorativos que recebem são relativamente bem documentados e datados. Todos esses dados vêm sendo compilados em artigos e livros na Europa, a partir da associação entre documentação histórica acerca da sua produção e comércio, e de estudos arqueológicos.

Em contextos internacionais, desde a década de 1970, grande atenção foi dada à técnica de manufatura de cachimbos e à tarefa de datá-los a partir da sua morfologia, usando parâmetros como o diâmetro do orifício da haste e a dimensão e formato do fornilho, entre outras características formais da peça. Ressalta-se que existem núcleos de estudo especializados em cachimbos de caulim, que coincidem, não por acaso, com antigos centros produtores: na Inglaterra, a Society for Clay Pipe Research, na Holanda, a Pijpelogische Kring Nederland, na Alemanha, a Arbeitskreis Tonpfeifen, e na França, a Académie Internationale de La Pipe. $\bigcirc$ trecho que se segue delineia os principais métodos de análise dos cachimbos, incluindo morfologia, marca de fabricante e decoração. Outros atributos e elementos passíveis de análise arqueológica aguardarão publicação subsequente para revisão, tais como queima da argila, marcas de uso, padrão de quebra, reciclagem e análises arqueométricas, botânicas e forenses. 
71. A título de curiosidade acadêmica, Oswald (1975) sugere que a ideia inicial desse método teria sido dele próprio.

72. Isto é problematizado em McMillan (2010, p. 70). A autora aponta que: "Although Harrington claims that he only used English pipe stem fragments (Harrington 1954:64), he does not say how he determined this. Dutch pipe stems are generally much thinner, and the bores smaller, than their English counterparts (Oswald 1975:115; Harrington 1978:64; Bradley 2000:116). If the original Harrington samples did include pipes from the $\mathrm{Ne}$ therlands, then samples lacking Dutch pipes would produce formula results much earlier than the predicted mean they are being compared to".

73. Harrington (1978).

74. Entre 1620-1650, é mais popular o furo com a dimensão de 8/64"; 16501680, 7/64"; 1680-1710, 6/64"; 1710-1750, 5/64"; 1750-1800, 4/64"

\section{1. Métodos estatísticos aplicados ao estudo dos cachimbos de caulim}

4.1 1. 1. Método de datação a partir do diâmetro do furo da haste

Entre os métodos estatísticos usados para estimar a datação de cachimbos de caulim e dos contextos nos quais eles aparecem, o mais difundido e utilizado é o do furo da haste. Esse método estatístico foi elaborado por Harrington, em 1954.71 Ele se baseia na observação de que a dimensão do furo da haste diminui cerca de 1/64" a cada 30 ou 50 anos (entre c. 1620-1800), devido ao aprimoramento da técnica de fabrico do fio de ferro que molda o furo. Como na maior parte das coleções arqueológicas de cachimbos a haste é o elemento predominante, a técnica é especialmente útil. Interessa também apontar que Harrington comparou sua técnica com a seriação elaborada por Adrian Oswald para fornilhos, que será detalhada mais adiante, e as datações oferecidas por ambos os métodos correspondem suficientemente bem.

Para elaborar seu método, Harrington se utilizou de uma amostra específica, composta por cachimbos ingleses, ${ }^{72} \mathrm{com}$ cerca de 330 exemplares no total e 66 fragmentos para cada um dos cinco períodos selecionados. Esses períodos foram escolhidos de acordo com as peças datadas disponíveis e suas extensões diferem entre si. Um cuidado que se deve ter durante a tomada das dimensões é com a boquilha, que poderá ser mais larga do que o restante da haste, pela passagem do fio contendo material durante sua retirada. Nesse caso, deve-se medir a extremidade quebrada.

Nota-se, no histograma produzido por Harrington, ${ }^{73}$ que há uma sobreposição de uso de dimensões distintas em cada um dos períodos. Em outras palavras, por exemplo, no período inicial, de 1620-1650, ocorrem furos de dimensões 9/64", 8/64" e 7/64". Porém, a predominância é do furo de dimensão 8/64". Assim, há uma maior popularidade, em cada período, de uma dimensão específica que diminui com o tempo, até c. 1800,74 quando o furo estabiliza em 4/64". Por essa razão, Harrington considera seu método impreciso para datas a partir do fim do século XVIII.

Além do limite temporal, outra restrição do uso dessa técnica é a necessidade de amostras em grande número. Para Harrington, é "estatisticamente impensável" aplicar a técnica a um único fragmento. Posteriormente, Oswald reitera essa afirmativa, discutindo também o risco de se trabalhar com amostras muito pequenas. Nas palavras de Harrington, deve-se usar de "senso comum" para enquadrar uma coleção em período específico e/ ou datar o sítio ou estrato. Nesse sentido, o arqueólogo aponta que um único fragmento poderá ser datado em um período não muito maior do que 100 anos, o que isoladamente poderá não ser muito útil, mas esse dado poderá ser conjugado com outras evidências.

Uma última limitação do método de Harrington é que amostras contendo cachimbos fabricados em outros países, em especial na Holanda (pela sua maior 
propagação), podem contaminar o resultado. $\bigcirc$ próprio Harrington aponta para esse fato, esclarecendo que o diâmetro do furo da haste de um cachimbo holandês provavelmente será menor que o de um cachimbo inglês de um mesmo período. ${ }^{75}$

Posteriormente, o método de Harrington foi refinado por Binford em 1961, que o considerava um método desajeitado de apresentar dados. Uma crítica apontada por Binford ao método anterior foi a dificuldade em correlacionar os períodos de 30-40 anos dispostos no histograma base proposto por Harrington com os depósitos e amostras arqueológicas encontradas.

Binford, então, oferece uma fórmula matemática de regressão linear que estima a data média para o período de acúmulo da amostra. Aponta-se de antemão que, como o método de Harrington, o de Binford também apresenta a imprecisão temporal a partir de fins do XVIII, pela mesma razão da estabilização da espessura do fio de ferro. Contudo, Binford aponta o marco de c. 1780 dos depósitos, para a perda de validade da fórmula. Outras constrições ao uso da fórmula são: a amostra a ser datada deve ser aleatória, representativa ${ }^{76}$ e apresentar uma taxa constante de acúmulo do depósito. ${ }^{77}$ Ainda, o desvio-padrão deverá indicar uma estimativa do período de acúmulo do depósito em questão.

$Y=1931.85-38.26 X$

$Y=$ tempo em anos

$X=$ Média aritmética das medidas de diâmetro do furo das hastes em dada coleção de cachimbos

Ao analisar uma coleção na Virgínia (Williamsburg) com a fórmula de Binford, Hume aponta para a necessidade de se dispor ao menos de 900 fragmentos para um resultado confiável. Aponta ainda para uma diminuição da acurácia dos resultados a partir da data de 1760 (portanto, ainda anterior ao marco oferecido por Binford na sua publicação de 1978) e para a total ineficácia da fórmula para coleções do XIX, devido, entre outros, à impossível redução do furo da haste para além de 4/64" e, também, ao uso mais frequente de cachimbos mais curtos. ${ }^{78}$

Hanson, em 1969, critica a fórmula proposta por Binford e indica uma relação não linear entre tempo e diâmetro da haste. A regressão não linear seria mais aguda entre 1620-1725 (com a diminuição do furo da haste mais rápida) e gradualmente se tornando menos aguda a partir dessa data (diminuição do furo da haste mais lenta). Sua fórmula também apresenta as mesmas constrições que os métodos anteriores (deve ser composta por cachimbos ingleses, aleatória, ampla e não ultrapassar o século XVIII). ${ }^{79}$ Apesar de concluir que mais pesquisa deveria ser feita para refinar os dados e as fórmulas, Hanson, considerando os diferentes períodos e taxas de diminuição do furo da haste, propõe fórmulas distintas para cada bloco de tempo.

Posteriormente, Heighton e Deagan, visando confirmar a proposta de Hanson, propõem uma equação logarítmica geral. ${ }^{80}$
75. Sobre o método desenvolvido por Harrington, ver Deetz (1996), Gary (2007), Harrington (1978), Mallios (2005), Oswald (1975).

76. Aponta-se que Binford (1978) não oferece um valor absoluto para o que considera representativo.

77. Binford (1978) aponta que essas limitações também deveriam ser aplicáveis ao método de Harrington.

78. Sobre o método desenvolvido por Binford, ver Binford (1978), Hume (1985), Oswald (1975).

79. Sobre o método desenvolvido por Hanson, ver Hanson (1971), Mallios (2005), Oswald (1975).

80. Heighton; Deagan (1971), Mallios (2005). 
81. Deetz (1987), Mallios (2005), Oswald (1975).

82. Barca (2012), Hume (1985), Mallios (2005), Pierce (2007).

83. Duco (1987).

84. Duco (1987); Oswald (1975, p. 29; 94).
Após esse esforço estatístico de vários autores, Deetz reafirmou o valor do método Harrington em apresentar alguns aspectos qualitativos do dado arqueológico (especialmente no uso de histogramas para demonstrar a duração e a intensidade das ocupações). Além disso, Deetz afirma que a definição dos períodos de ocupação (por meio do desvio-padrão) no método de Binford seria menos precisa que a do método Harrington. Além disso, Deetz dá pouco valor ao dado "data média". Oswald adiciona ainda outra complicação ao uso de estatísticas baseadas no furo da haste, a das variações locais. Esse autor finaliza a questão afirmando que as informações morfocronológicas para fornilhos são mais confiáveis, o que Mallios corrobora. ${ }^{81}$

\subsubsection{Outros métodos quantitativos}

Alguns outros métodos quantitativos foram empregados no estudo de cachimbos, buscando especialmente a definição de datas e períodos de ocupação.

A datação pela extensão da haste se baseia na premissa de que o tamanho da haste muda conforme o tempo, da seguinte maneira: Os primeiros cachimbos, no final do XVI, mediam c. 3,5", podendo chegar a c. 3,25". Já no início do século XVII, as hastes mediam de 6 a 8"; e, no terceiro quartel do XVII, chegavam a 11" e 12". A partir dos anos 1700, as hastes apresentavam c. 13-13,5". No início do XVIII, foram introduzidos cachimbos longos, chamados alderman ou straws, medindo c. de 18" (45 $\mathrm{cm})$, usados pelas classes mais abastadas. A partir do final do XVIII, outros cachimbos extralongos também foram utilizados, embora não largamente. Eram os chamados churchwarden (ou yard of clay), medindo até 36" $(90 \mathrm{~cm}$ ). A ideia dos cachimbos extralongos era segurar o fornilho enquanto a mão se apoiava no braço da cadeira. A partir do século XIX, voltam a ser populares cachimbos mais curtos, de c. 9".

Apesar de haver parâmetros objetivos de extensão da haste para comparação com coleções arqueológicas, a utilização desse parâmetro cronológico é dificultada por dois fatores. Um deles é que, durante o século XIX, cachimbos com hastes longas do tipo "churchwarden" continuaram a ser produzidos, concomitantemente aos cachimbos curtos. Ainda, a maior limitação desse método está na dificuldade em encontrar hastes completas em contextos arqueológicos. ${ }^{82}$

Já o método estatístico para fornilhos, elaborado pelo holandês F. H. W. Friedrich e usado em especial na Holanda, parte da premissa de que o fornilho cresce com o tempo, buscando mapear a cronologia das mudanças gerais nas suas proporções, e considerar transformações regionais. Segundo Duco, ${ }^{83}$ as medidas tomadas foram largura do fornilho (L), altura do fornilho $(H)$ e diâmetro da boca do fornilho (D), e a multiplicação desses três parâmetros seria comparada a uma evolução cronológica. Contudo, Duco aponta que um dos problemas da fórmula é não levar em conta a espessura das paredes do fornilho, que são mais finas para exemplares de melhor qualidade. Além disso, conclui que a correlação desses parâmetros volumétricos não condiria com exatidão com os indicadores cronológicos, especialmente para o século XVII. ${ }^{84}$ 


\subsection{Sequências morfocronológicas}

\subsubsection{Cachimbos ingleses}

A primeira descrição histórica de um cachimbo inglês de argila data de 1573, por William Harrison, em seu texto Great Chronologie. O autor compara a forma do cachimbo à de uma concha de servir alimentos líquidos. Já no XVII, o fornilho é maior, com uma "barriga" às vezes bastante pronunciada. Essas e outras transformações formais continuaram acontecendo nos cachimbos de caulim na Europa ao longo dos séculos, possibilitando a construção de tipos baseados em atributos morfológicos e suas associações com períodos específicos.

Um importante estudo da evolução cronológica das formas dos cachimbos ingleses foi feito pelo arqueólogo Adrian Oswald, em 1951, ao qual sucederam vários refinamentos feitos pelo próprio autor. $\bigcirc$ estudo levou em consideração coleções de cachimbos datadas pelos seus contextos arqueológicos, especialmente produzidas em Londres; cachimbos marcados com datas; representações em desenhos e pinturas de época; e, em menor grau, identificação de marcas de fabricantes comparadas à documentação primária.

Foi mapeado, apesar de variações regionais, que mudanças morfológicas nos cachimbos ingleses ocorriam a cada 30 anos aproximadamente. De modo geral, no início do século XVII tinha-se fornilhos muito pequenos, com uma circunferência central maior que a borda, tanto nos cachimbos com pedúnculo achatado (em heel), quanto os com pedúnculo pontudo (em spur). ${ }^{85} \mathrm{~A}$ altura dos fornilhos aumenta gradativamente durante o século XVII. ${ }^{86} \mathrm{~A}$ partir do XVIII, o ângulo entre o fornilho e a haste se torna mais reto e o formato dos fornilhos, mais cilíndrico. Ainda no início do XVIII, os cachimbos melhoram em qualidade, com acabamento mais liso e hastes e paredes mais finas. $\bigcirc$ topo da borda passa a ser cortado paralelamente à haste. $O$ ângulo formado entre o fornilho e a haste, que diminui com o tempo, na metade do século XIX, chega perto de um ângulo reto. ${ }^{87}$

Oswald aponta que a sequência feita com base em cachimbos de Londres, com 33 tipos, pode ser amplamente utilizada para cachimbos ingleses, especialmente para datas anteriores a 1640, já que este era então o principal centro produtor. Após essa data, sua sequência simplificada (com 30 tipos) para os cachimbos produzidos na Inglaterra como um todo é útil como guia geral de referência. Contudo, em alguns casos, a sequência geral não é aplicável quando tendências locais são predominantes. Isso ocorre para cachimbos de Broseley, por exemplo, para onde foi produzida uma sequência regional. Outras sequências regionais são oferecidas por Oswald, incluindo Escócia, região nordeste e Yorkshire, Broseley, região sul, região oeste, entre outros. Outros autores também se dedicaram às sequências cronológicas: Sequência de York, criada por Lawrence, em 1979, e Sequência de Hull, por Watkins, 1979.88 Posteriormente, Hume publicou uma revisão simplificada com base no trabalho de Oswald e Atkinson, adicionando alguns exemplares estadunidenses.
85. Ayto (2002) aponta para uma possível razão para a forma do pedúnculo pontudo: como as hastes dos cachimbos se tornavam mais longas, com o pedúnculo pontudo ele poderia ser apoiado em uma mesa, durante o fumo, sem marcá-la.

86. Sugeriu-se, no início dos estudos sobre o cachimbo de caulim, que o aumento do fornilho fora uma resposta ao barateamento do tabaco (Oswald, 1975)

87. Higgins (2009), Mallios (2005), Oswald (1975).

88. Susan White (2004). 


\subsubsection{Cachimbos holandeses}

As formas dos cachimbos holandeses, apesar de similares às formas inglesas no século XVII, tomaram seu próprio curso, além de terem se alterado menos do que aquelas ao longo do tempo.

Duco produziu uma sequência cronológica de tipos segundo critérios morfológicos, similar àquelas de Oswald e Atkinson, para os cachimbos holandeses (ver a Tabela 2). Algumas tendências básicas são análogas à evolução morfológica dos cachimbos ingleses, tais como o aumento do fornilho e mudança na angulação entre fornilho e haste em direção a um ângulo reto. Contudo, como as alterações na morfologia dos cachimbos holandeses foram menos frequentes ao longo dos séculos, as sequências cronológicas apresentam menos tipos que aquelas produzidas para cachimbos ingleses e alguns tipos holandeses não apresentam correlatos nas sequências inglesas, o que facilita seu uso na identificação de procedência. A sequência de Duco foi revista posteriormente por Oostveen, que propôs leves alterações.

Tabela 2: Comparação entre as cronologias de tipos de cachimbos holandeses

\begin{tabular}{|c|c|c|}
\hline TIPO & DUCO (1987) & OOSTVEEN (2001) \\
\hline Primeira Geração & $1580-1610$ & $1580-1620$ \\
\hline Bicônico & $1630-1695$ & $1610-$ fim XVII \\
\hline Funil & $1680-1730$ & $1670-1740$ \\
\hline Ovoide & $1730-1960$ & $1730-X X$ \\
\hline Gancho & $1730-1960$ & $1730-X X$ \\
\hline Base arredondada / sem pedúnculo & $1740-1960$ & $1730-X X$ \\
\hline
\end{tabular}

Duco apresenta três tipos de cachimbos da primeira geração, mas estes, de forma geral, apresentam haste contínua ao fornilho, argila fina e às vezes azulcinzenta, não são polidos, não apresentam anel serrilhado na borda do fornilho, que é cortada. Mais comumente, estes ocorrem sem marcas de fabricante, sendo que, nesse tipo/período, o único cachimbo muito decorado é o de um peixe com a boca aberta.

O modelo bicônico inicialmente era mais produzido em Amsterdã, até c. 1630. Após esse momento, Gouda torna-se o centro predominante de produção. Esses cachimbos apresentam tanto fornilhos polidos, como também sem tratamento de superfície. Há alguns bastante rebuscados, com decoração moldada em relevo (estilo barroco), que serão detalhados mais adiante. Apesar da existência de cachimbos bicônicos ornados, continua sendo predominante o cachimbo sem decoração. 
No último quartel do século XVII, esse modelo desaparece em favor do modelo em forma de funil, sendo por ele substituído em Amsterdã por volta de 1690. Esse novo tipo sempre recebe um acabamento arredondado na borda do fornilho. São conhecidos exemplares marcados, com polimento ou sem tratamento de superfície no fornilho.

Por volta de 1730, o modelo ovoide é introduzido no mercado de Amsterdã. Na segunda metade do século XVIII, mais de 95\% dos cachimbos de caulim eram desse modelo, demonstrando sua ampla popularidade. ${ }^{89}$ Este continua em uso até meados do século XIX, como evidenciado pelos muitos achados arqueológicos. $\bigcirc$ modelo ovoide apresenta polimento, na maior parte dos casos, e vários possuem marcas de fabricante no pedúnculo.

Quase paralelamente ao modelo ovoide, ou seja, no início do século XVIII, o modelo gancho passou a ser produzido. Era feito especialmente para exportação e para competir com cachimbos de produção inglesa, tendo sido introduzido em Gouda por volta de 1730. Uma pesquisa desenvolvida por Oostveen mostrou que esse modelo constituía apenas 0,4\% do mercado de Amsterdã durante o período no qual foi produzido. Contudo, por volta de 18301840, houve um renascimento do modelo gancho naquela cidade, devido à introdução do modelo Izabé (que será apresentado brevemente mais adiante).

O modelo de base arredondada desenvolve-se por volta de 1730, como os últimos dois modelos apresentados; este, contudo, sem qualquer pedúnculo e, predominantemente, a base recebe marca de fabricante. A popularidade desse modelo cresce gradualmente no século XIX, mas nunca foi popular como o tipo ovoide..$^{90}$

\subsection{Marcas de fabricante}

Inscrições de marcas de fabricantes em cachimbos de caulim são bastante comuns, podendo auxiliar discussões que envolvem cronologia e relações comerciais. Contudo, deve-se atentar para o fato de que as iniciais de um fabricante de cachimbos nem sempre podem ser atribuídas a um indivíduo específico. As marcas podiam ser vendidas, alugadas ou herdadas, tal como podem ser copiadas, no mesmo período ou até décadas depois.

Os fabricantes, considerando todos os momentos distintos da produção de cachimbos, acabaram se utilizando de praticamente toda a área da peça para imprimirem seus referentes. Em outras palavras, as marcas podem se localizar no pedúnculo (na base ou na lateral), na haste, nas laterais ou na traseira do fornilho, ou seja, em quase todo o cachimbo. Elas podem ser alfabéticas, numéricas, iconográficas, ou mesclar esses elementos. Alguns exemplos de marcas iconográficas são cenas cotidianas, objetos triviais, eventos, pessoas ou produtos publicizados pelo fabricante de cachimbos. Era possível também inserir no cachimbo propagandas requeridas pelo consumidor (quando empresas) ou marcas de distribuidores. ${ }^{91}$
89. Esse estudo de Oosteveen (2001) levou em consideração 20 mil fragmentos de cachimbos coletados na cidade de Amsterdã.

90. Ver Oosteveen (2001) e Duco (1987).

91. Sudbury; Gerth (2011). 
92. Sobre esse tópico, ver Meulen (2003), Duco (1987), Oswald (1967; 1975).

93. Oswald (1975, p. 115). Tradução nossa.
Indica-se, ao buscar a marca do fabricante, primeiro datar o período de fabricação pela sequência morfocronológica dos fornilhos (caso disponíveis), uma vez que poderão ocorrer mais de um fabricante em momentos distintos operando com as mesmas iniciais. Além disso, deve-se considerar que o estilo da marca e o local de inserção da marca do fabricante também têm implicação cronológica.

Na Inglaterra, no século XVII, as marcas eram posicionadas na base do pedúnculo achatado. No caso de cachimbos com pedúnculo pontudo, na primeira metade do XVII, podiam aparecer em fornilhos e, ao final daquele século, moldadas nas laterais do pedúnculo pontudo. A partir de c. 1650, marcas incisas ou moldadas podiam ser posicionadas na traseira de fornithos ou na lateral destes, em alguns casos. A partir de 1690, podiam aparecer também moldadas em apenas uma das laterais do fornilho. Marcas em fornilhos foram menos populares do início do século XVIII ao início do XIX (quando voltaram a ser usadas, incisas). Em hastes, iniciais incisas podiam aparecer desde c. 1650, enquanto nomes completos, por volta de 1670. Inscrições moldadas na haste ocorreram somente por volta de 1800. Na Holanda, no século $\mathrm{XVII}$, as marcas de fabricante eram geralmente posicionadas incisas na base do pedúnculo. No XVIII, podiam aparecer incisas na base do pedúnculo ou moldadas na lateral do fornilho. No XIX, nas laterais do pedúnculo (que diminuiu de tamanho) ou moldadas na lateral do fornilho. Inscriç̃ẽes nas hastes foram mais comumente incisas no século XVII e mais comumente moldadas no XIX. ${ }^{92}$ Oswald procurou estabelecer uma distinção entre marcas de fabricante inglesas e holandesas, como se segue:

Marcas: Uma classificação ampla das marcas mostra cinco tipos:

1. Marcas numerais com e sem coroa;

2. Marcas com uma ou duas letras, com ou sem coroa;

3. Marcas decorativas, tais como leiteira ou moinho de vento, por vezes com coroa;

4. Símbolos, tais como cruz ou roda:

5. Marcas com três letras.

Geralmente, os tipos 1 e 3 não ocorrem nos cachimbos ingleses, os tipos 2 coroado e 5, raramente. Marcas nas laterais dos cachimbos ou pedúnculos do tipo pontudo são características de cachimbos holandeses. ${ }^{93}$

Desse trecho transcrito, ressalta-se a exclusividade de marcas numéricas e de marcas decorativas e cênicas entre os holandeses; a predominância de marcas coroadas e de três letras em marcas alfabéticas nos cachimbos holandeses.

Várias marcas de fabricantes, especialmente as iconográficas, também apresentam apelo estético, algumas até mesmo dispostas em áreas grandes e visíveis dos cachimbos, como os fornilhos. Algumas, também, eram posicionadas na sua porção traseira, de forma que ficava visível para o fumante. Uma vez que muitas delas são indissociáveis dos padrões decorativos, algumas informações sobre as marcas serão apresentadas entremeadas na descrição que se segue. 
Além das transformações que ocorreram na morfologia dos cachimbos, é possível associar alguns estilos decorativos aos seus locais e períodos de fabrico. Contudo, a questão da origem de produção dos cachimbos encontrados arqueologicamente não deve ser tomada como simples. Deve-se atentar para difusão de estilos internamente na Europa, tal como o comércio entre os países, mesmo entre centros produtores. Outro complicador é o fato de que vários centros produtores competidores imitavam cachimbos mais sofisticados e caros, por exemplo, os de Gouda nos séculos XVII e XVIII, que eram emulados em versões mais rudimentares e com pior acabamento.

Assim, Oswald, preocupado com a identificação dos cachimbos holandeses que eram importados para a Inglaterra, apesar da grande produção interna, sumarizou algumas diferenças de decoração entre os cachimbos holandeses e ingleses:

Fornilhos: Exemplares holandeses do início do século XVII podem ser distinguidos por uma marcada protuberância e frequentemente uma curva para dentro logo acima da base. $\mathrm{Na}$ segunda metade do XVII, os fornilhos são mais alongados do que os cachimbos ingleses contemporâneos, frequentemente com um alargamento na borda do fornilho, e o polimento fica mais comum. Os cachimbos holandeses do século XVIII e do XIX apresentam uma curva ovoide, enquanto os cachimbos ingleses são normalmente paralelos.

Serrilhado: Essa decoração na borda do fornilho está presente nos cachimbos holandeses ao longo da sua história, mas está normalmente ausente em cachimbos ingleses após o início do século XVIII.

Hastes: Nos cachimbos holandeses elas se tornam notadamente mais finas que nos cachimbos ingleses, ao final do século XVII, e essa espessura não é atingida pelos ingleses até o final do XVIII.

Acabamento de superfície: Os fornilhos e hastes dos cachimbos holandeses são normalmente polidos atingindo um lustre (ou brunidura) forte, após c. 1700. A execução de decoração moldada é quase sempre superior em detalhes e cachimbos holandeses moldados decorativos parecem começar já desde o início da sua produção, em c. 1610.

Dureza: Como um teste rudimentar, é possível riscar a superfície de cachimbos holandeses do século XVII com um canivete sem muito esforço. Aparentemente, é mais difícil fazer isso com cachimbos ingleses. ${ }^{94}$

Dessas características transcritas, que também incluem um componente morfológico, ressalta-se especialmente a presença do serrilhado na borda do fornilho unicamente no cachimbo holandês após o século XVIII, e a presença de decoração intrincada moldada apenas em cachimbos holandeses no início do XVII, que poderão auxiliar a identificação dos cachimbos.

A seguir são apresentados em linhas gerais os estilos mais característicos da Inglaterra e da Holanda, para nortear a identificação de procedência e período. 
95. Para mais informações sobre os primeiros cachimbos de caulim da Inglaterra, ver Bradley; DeAngelo (1981), Higgins (2009), Oswald (1967; 1975, p. 96).

96. Oswald (1967) e Higgins (2009) usam o termo Fluted, mas esse tipo também é referido em outras ocasiões como Scalloped ou Ribbed. Sudbury e Gerth (2011) preferem o termo ribbed, tal como Jackson; Beckey; Backer (1991).

\subsection{Decoração de cachimbos ingleses: síntese}

$\mathrm{Na}$ Inglaterra, os primeiros cachimbos, ainda no século XVI, ocasionalmente eram marcados no pedúnculo achatado com uma letra ou símbolos no pedúnculo ou haste. Já no XVII, o serrilhado na borda se torna comum, e, às vezes, também o polimento. Entre os possíveis exemplares comumente encontrados em sítios de Londres desse período inicial estão carimbos incisos nas hastes, com motivos de flores-de-lis ou cruzes, em losangos; contudo, há alguma dúvida se tratase de exemplares holandeses. Entre outros, há também a luva de ferro ou manopla (gauntlef) incisa. ${ }^{95}$

A decoração moldada não aparece até c. 1650. A partir desse momento, torna-se popular o Mullberry pipe, que apresenta decoração moldada na lateral do fornilho, em círculos em relevo, formando um desenho semelhante a um cacho de uvas, lembrando também padrões holandeses do período. Porém, a maior parte dos cachimbos do século XVII não apresentava muita decoração, sendo que os cachimbos mais decorados desse período são atribuídos a uma origem holandesa.

Já no século XVIII, os cachimbos raramente recebiam decoração incisa, com exceção do serrilhado na borda. Em Londres, especialmente na segunda metade daquele século, tornou-se comum marcar com carimbo o fornilho. Por exemplo, a partir de cerca de 1770, passa a ser comum aplicar por incisão o brasão de armas de Londres, na parte traseira dos fornilhos. Já a decoração moldada da primeira metade dos Setecentos era feita mais frequentemente nas hastes (volutas e padrões geométricos). A partir da segunda metade do XVIII, a decoração moldada nos fornilhos se torna gradualmente mais comum, incluindo brasões, símbolos de casas públicas, de regimentos militares, emblemas maçônicos e penas do Príncipe de Gales. A partir de 1760, também os acanalados (referidos como ribbed ou fluted e similares aos acanalados holandeses, denominados lobben ou ribbel), 90 decoração em folhagem de carvalho acompanhando a frente do fornilho (padrões fitomorfos para encobrir as linhas do molde no fornilho, mas esses eram raros). Ao final do século XVIII, outros motivos foram criados. Estes, chamados fancy clays ou fancies, receberam alguma influência dos cachimbos de espuma do mar. Entre alguns exemplos de fins do século XVIII a meados do XIX estão os comuns cachimbos de garra, os com espinhos, antropomorfos de personagens conhecidos como Nelson, Rainha Vitória, Príncipe Albert, sereias e negros, ou motivos referentes a balões e críquete, e os cachimbos da Royal Ancient Order of the Buffaloes, cujos fornilhos comumente portam moldadas a inscrição "R A $\bigcirc$ B" e uma cabeça de búfalo.

No século XIX, muito pouca decoração incisa era aplicada, geralmente restrita a padrões geométricos e florais ao redor de nomes nas hastes, e volutas e brasões nos fornilhos. A decoração moldada se torna bem mais popular e elaborada, com os já mencionados fancies, os acanalados e fitomorfos, entre outros. Ainda, as pontas das hastes (boquilhas) podiam receber esmalte. Os tipos chamados de cutty começaram a ser produzidos a partir de c. 1850. Muitos cachimbos recebiam marca moldada com o nome do fabricante por extenso na 
haste ou iniciais na lateral do pedúnculo. Marcas carimbadas no fornilho também foram comuns nesse período.

\subsubsection{Decoração de cachimbos holandeses: síntese}

Em meados do século XVII, quando o fumo se tornou mais difundido nos ambientes civis, também ocorreu certa padronização da qualidade nos cachimbos fabricados pelos principais centros produtores da Holanda, especialmente Gouda e Amsterdã. Considerando o quesito qualidade, há três tipos distintos produzidos em Gouda. O tipo slegte era o mais simples, mais barato, com a haste áspera e curta, e sem decoração. $\bigcirc$ acabamento era simples e a peça poderia receber carimbo no pedúnculo. Alguns cachimbos decorados na lateral do fornilho também podem pertencer a essa categoria, porém eram um pouco mais caros do que os sem decoração. Nos slegte, também, recorrentemente o serrilhado na borda do fornilho não era totalmente circular, assim como era visível o mau nivelamento da junção do molde. O slegte por vezes apresenta a letra "S" moldada na lateral do pedúnculo, indicando sua qualidade inferior e menor preço. Contudo, apenas no século XVIII esse termo começou a ser empregado. Em decorrência da queda de preços do tipo intermediário, a ser descrito a seguir, em 1740 ele passou a ser marcado com a letra "S" em ambos os lados do fornilho. ${ }^{97}$

segundo tipo, fijn, produzido a partir de meados do século XVII, é de maior qualidade que o primeiro, com superfície polida, onde são visíveis as estrias de polimento com ágata ou outro instrumento, bom acabamento nas linhas de molde, frequentemente com decoração na haste e marca de fabricante no pedúnculo.

$\bigcirc$ tipo porceleijne ${ }^{98}$ era o de melhor qualidade, recebendo seu nome devido ao brilho obtido pelo polimento com ágata. Era similar ao tipo fijn, mas com melhor acabamento, inclusive nas costuras do molde, pois, após a queima, era mergulhado em uma mistura de cera que o deixava brilhoso. Este foi o cachimbo que deu a Gouda sua reputação. Contudo, arqueologicamente é difícil distinguir esses dois tipos. Inclusive, essa similaridade existia também na época, e foi a partir da sua introdução e popularização que os cachimbos fijn enfrentaram competição e passaram a ser distinguidos dos sledge pela marcação desses.

Como mencionado, vários cachimbos bicônicos, mesmo produzidos em Gouda, recebiam pouca decoração, por vezes limitada ao serrilhado na borda do fornilho.

Em termos de técnica de aplicação, os cachimbos, quando decorados, poderiam ser ornados por incisões (carimbadas) ou pelo molde que thes dá a forma geral. Inicialmente, as marcas com rosa, acompanhadas ou não de coroa ou de iniciais, indicavam melhores cachimbos. A marca Rosa Tudor incisa, em especial como marca de fabricante em pedúnculos, aparece na produção holandesa. Nesse período, também é comum, além da marca, decoração na haste, em especial a flor-de-lis, envolta ou não por losango (ou diamante). ${ }^{99}$ Essa decoração incisa, quando aplicada na haste, frequentemente indicava o melhor local para segurar o
97. Duco (1980a,1980b, 1993), Wacke (2014), Walker (1971).

98. Esses cachimbos não são de porcelana, apesar da denominação sugestiva.

99. Sobre a Rosa Tudor e a flor-de-lis, ver Bradley; DeAngelo (1981), Dallal (2004; s.d), Gary (2007), Oswald (1975, p. 96) 
100. Bradley e DeAngelo (1981) apontam essa flor de pontos como uma variante da Rosa Tudor, também atribuindo sua procedência e período à Holanda do século XVII.

101. Gary (2007), Oswald (1967). cachimbo (onde está localizado o centro de gravidade da peça). Mais tarde, após c. 1650, o centro de gravidade passou a ser marcado frequentemente pela decoração ágil das bandas anelares simples ou mesmo com bandas mais sofisticadas, método mais barato inventado em Gouda. Outras bandas anelares mais complexas se sucederam, por exemplo, incluindo cruzes, pérolas etc. As decorações moldadas em relevo são raras, porém mais raras são as decorações em relevo que incluem também a haste. Os motivos são geralmente fitomorfos e florais, e, com menos frequência, os geométricos.

No século XVII, há cachimbos decorados em relevo moldado na lateral do fornilho (zijmerkpijpen), especialmente incluindo flor-de-lis, rosa em pontos ${ }^{100} \mathrm{e}$ ramos. Ainda na primeira metade do século XVII, foi desenvolvido um tipo especial de cachimbos moldados, com decoração intrincada em relevo em toda a peça, denominado estilo barroco. Aparecem alguns poucos exemplares a partir da década de 1610, mas é a partir do início da década de 1630 que esse estilo toma força, porém em diversidade limitada de motivos. Davey, com base no trabalho de Don Duco, aponta algumas características desse estilo, ramificando-o em quatro tipos. $\bigcirc$ barroco tipo 1 são pequenos fornilhos e hastes ornadas, com motivos florais em baixo relevo, feitos em molde, enquanto o pedúnculo achatado frequentemente apresenta carimbo de rosa. $O$ barroco tipo 2 tem forma similar ao primeiro, porém menos decorado que esse. $\bigcirc$ barroco tipo 3 apresenta fornilho similar ao tipo 2, sem pedúnculo, decorado com florais encapsulando a metade inferior, e o restante com poucos elementos. $\bigcirc$ barroco tipo 3 é possivelmente o mais comum, o cachimbo do Jonas. $\bigcirc$ cachimbo figura a lenda de sir Walter Raleigh, personalidade que representa a introdução do tabaco na Europa, sendo engolido por um crocodilo devido à quantidade de tabaco no seu corpo. Esse cachimbo é muito mais comumente referenciado como cachimbo do Jonas, devido à história bíblica entre o profeta e a baleia (ou serpente). ${ }^{101}$ Ele foi produzido inicialmente na Inglaterra, até ser proibido. A partir daí é comumente atribuído à origem holandesa. Há referências de cachimbos de Jonas fabricados em Amsterdã, em Gouda e em Gröninger, na Holanda, mas também raras menções a sua produção na Dinamarca e na Alemanha. Na produção de Gouda, o Jonas era feito por moldes de quatro partes, uma técnica que requeria habilidade, com as duas principais formando o corpo da peça, uma terceira parte para o rosto e a última para as costas. $\bigcirc$ chapéu era feito por um anel acoplado às duas partes principais do molde. A decoração também pode aparecer no pedúnculo, como uma simples baleia. Foi adotado por marinheiros e soldados como símbolo, especialmente entre 1630-1680. Os mais antigos carregam a inscrição "IONAS ANNO 1632" e, após a década de 1650, a maioria deles vem de Gouda, diminuindo em importância a partir da década de 1680.

A partir da metade do século XVII, com esses exemplares altamente sofisticados, a popularidade da marca de fabricante aumenta ainda mais, sendo Gouda o centro da propagação de estilos novos le, como já mencionado, não somente os estilos dos cachimbos eram imitados, mas também as marcas de 
fabricante). Em fase posterior, não somente Gouda produzia o estilo barroco, de modo que outras variações apareceram, menos rebuscadas.

Os cachimbos em forma de funil, desenvolvidos entre os séculos XVII e XVIII, aparecem com decoração simples (apenas serrilhado na borda do fornilho) e em várias decorações, entre elas nacionalistas ou naturalistas, heráldica, incluindo brasões como as armas das Sete Províncias Unidas, e vida cotidiana, em especial com a marca iconográfica-decorativa na lateral do fornilho (zijmerkpijpen). Em Gouda, cachimbos com hastes de meio metro são fabricados como itens de luxo.

Os cachimbos acanalados holandeses (lobben ou ribbell, similares aos cachimbos ingleses nomeados de ribbed, scalloped ou fluted, aparecem na segunda metade do século XVIII, em tipo simples e em decoração fina.

No século XIX, Gouda para de produzir os tipos de menor qualidade e, na segunda metade do XIX, a popularidade de Gouda se esvai, de modo que os cachimbos holandeses a essa época passam a receber influências da França e da Bélgica, com cachimbos mais curtos. O cachimbo com decoração na lateral do fornilho (zijmerkpijpen) e em formato de funil é substituído por modelos de haste curta, em formas ovoides. O modelo lzabé é um desses cachimbos mais curtos, na forma em gancho. Ainda persiste o padrão simplesmente serrilhado na borda do fornilho, agora com pequena marca de fabricante moldada na lateral do pedúnculo, em vez de localizar-se na base do mesmo. Alguns temas persistem (tais como heráldico, cenas e acanalado), com a introdução de alguns novos padrões, tais como o pontilhado ou perolado e o de espinhos.

\section{Considerações finais}

Os tópicos abordados neste artigo propositalmente enfatizaram questões técnicas, tanto da produção histórica dos cachimbos de caulim, quanto da análise arqueológica desses. Apesar de várias outras discussões serem possíveis, necessárias e interessantes, no que se refere ao estudo dos cachimbos de caulim e das relações sociais e culturais que envolveram a sua produção e uso, é sobre seus aspectos mais materiais que nos debruçamos neste momento, particularmente no que tange seu potencial cronológico. Espera-se que essa revisão seja bemsucedida em divulgar algumas das bases principais para estudos mais aprofundados sobre o tema no Brasil, especialmente considerando que a bibliografia indispensável é estrangeira e, em vários casos, de difícil acesso. 


\section{REFERÊNCIAS}

ANDREWS, Phil. Riverside exchange, Sheffield: Investigations on the site of the Town Mill, Cutlers' Wheel, Marshall's Steelworks and the Naylor Vickers Works. Salisbury (UK): Wessex Archaeology, 2015.

ARNOLD, C. J. The clay tobacco-pipe industry: an economic study. In: PEACOCK, D. (Ed). Pottery and early commerce. Londres: Academic Press Inc., 1977, p. 313-336.

ATKINSON, David. Clay tobacco pipes bearing the Prince of Wales's feathers in the 19th century. Society for Clay pipe research, Bristol: [s.n], Newsletter 2, 1984.

; OSWALD, Adrian. London clay tobacco pipes. The Journal of the British Archaeological Association, [S.1.]: British Archaeological Association, v. 32, p. 171-227, 1969.

AULTMAN, Jennifer; BON-HARPER, Nick. DAACS Cataloging Manual: Tobacco Pipes. [S.1.]: [s.n.], 2003. Disponível em: <http://www.daacs.org/about-the-database/daacs-catalogingmanual/>. Acesso em: 21 set. 2016.

AYTO, Erick. Clay tobacco pipes. Princes Risborough: Shire Publications, 2002.

BARAM, Uzi. Clay tobacco pipes and coffee cup sherds in the archaeology of the middle east: artifacts of social tensions from the Ottoman past. International Journal of Historical Archaeology, New York, v. 3, n. 3, p. 137-151, 1999.

BARCA, Kathryn Gertrude. The best kind of long ones. Pittsburgh, 2012. 116 f. Dissertação (Mestrado) - University of Pittsburgh.

BÁRCENA, Carolina Cortés. Dutch and English clay pipes found in Santander (Cantabria, Spain). Journal of the Académie Internationale de la Pipe, Liverpool, v. 6, p. 83-87, 2013.

BELL, Max. Collecting American face pipes. [S.1.]: [s.n.], 2004. Disponível em: <http://www. fohbc.org/PDF_Files/Bell_ClayPipes.pdf> Acesso em: 1 fev. 2016.

BINFORD, Lewis. A new method of calculating dates from kaolin pipe stem samples. In: SCHUYLER, Robert. (Ed.). Historical Archaeology: a guide to substantive and theoretical contributions. New York: Bayood Publishing Copany Inc., 1978, p. 66-67. 
BRADLEY, James; DEANGELO, Gordon. European clay pipe marks from 17th century Onondaga Iroquois sites. Archaeology of Eastern North America, [S.1.]: Eastern States Archaeological Federation, v. 9, p. 109-133, 1981.

BRISTOW, Colin Malcolm; SCOTT Peter. The Ball Clay and China Clay Industries in Southwest England in 2000. In: (Ed.). Industrial Minerals and Extractive Industry Geology.

Bath: Geological Society Publishing House, 2002, p. 17-42.

CALADO, Marco; PIMENTA, João; SILVA, Rodrigo. Cachimbos de cerâmica provenientes da escavação do Caminho de Ronda no Castelo de São Jorge em Lisboa. Património: estudos, Lisboa: Instituto Português do Património Arquitectónico, v. 5, p. 83-95, 2003.

CASEY, Mary; LOWE, Tony. Darling Quarter, Darling Harbor Report. [S.1.]: [s.n.], 2013. Disponível em: <http://www.caseyandlowe.com.au/>. Acesso em: 11 fev. 2016.

CLARK, Gregory. Average Earnings and Retail Prices, UK, 1209-2010. [S.1.]: [s.n.], 2011. Disponível em: <https://www.measuringworth.com/datasets/ukearncpi/earnstudynew.pdf>. Acesso em: 22 mar. 2016.

COELHO, Antonio Vieira; SANTOS, Pérsio de Souza; SANTOS, Helena de Souza. Argilas especiais: o que são, caracterização e propriedades. Química Nova, São Paulo: Sociedade Brasileira de Química, v. 30, n. 1, p. 146-152, 2007.

COTTER, John. Excavations at Jamestown, Virginia: Site of the first permanent English settlement in America. Antiquity, [S.1.]: Cambridge University Press, v. XXXI, n. 121, p. 19-24, 1957.

DALLAL, Diane. The Tudor Rose and the Fleurs-de-lis: Women and iconography in SeventeenthCentury Dutch clay pipes found in New York city. In: RAFFERTY, Sean; MANN, Rob. Smoking and Culture: The archaeology of tobacco pipes in eastern North America. Knoxville: The University of Tennessee Press, 2004, p. 207-240.

. Apendix F: Pipe Analysis. [s.n.t.] Disponível em <http://s-media.nyc.gov/agencies/lpc/ arch_reports/122.pdf>. Acesso em: 11 mar. 2016.

DAVEY, Peter. Clay pipe found on the Salcombe Cannon Site. [s.n.t.] Disponível em: $<$ http:// www.swmag.org/index.php/clay-pipe>. Acesso em: 10 fev. 2016.

DEETZ, James. In small things forgotten: an archaeology of Early American life. Nova York: Anchor books, 1996.

DIXON, Kelly. Saloons in the wild West and taverns in Mesopotamia: explorations along the timeline of public drinking. In: ARCHER, Steven; BARTOY, Kevin. (Ed.). Between dirt and discussion: Methods, Methodology, and Interpretation in Historical Archaeology. New York: Springer, 2006, p. 61-79. 
DUCO, Don. Clay pipe manufacturing processes in Gouda, Holland. The archaeology of the clay tobacco pipe IV, Londres: BAR International Series, v. 92, p. 179-218, 1980a.

De Nederlandse Kleipijp. Leiden: Museu do Cachimbo, 1987.

Eighteenth century Clay pipes from Schoonhoven. The archaeology of the clay tobacco pipe IV, Londres: BAR International Series, v. 92, p. 109-114, $1980 \mathrm{~b}$.

2. 1984 .

The first Dutch bone-china pipe. Society for clay pipe research, Bristol: [s.n.], Newsletter

Kleipijpen. In: LENTING, J. et al. (Org.). Schans op de Grens: Bourtanger bodemvondsten (1580-1850). Sellingen: Stichting Vesting Bourtange, 1993.

DUGUAY, Françoise. Clay Pipes in New France, 1620-1760: Can Archaeometry be Helpful in Detecting Imitations? Society for Clay Pipe Research, Bristol: [s.n.], newsletter 81, p. 18-28, 2012.

FAVETON, Pierre. Autour du tabac: Tabatières, pipes, cigars, allumettes e briquets. Paris: Ed. Charles Massin, 1988.

FOX, Georgia. Interpreting socioeconomic changes in 17th-Century England and Port Royal, Jamaica through analysis of the Port Royal kaolin clay pipes. International Journal of Historical Archaeology, New York, v. 6, n. 1, p. 61-78, 2002.

FOX, R.; HALL, R. The Clay tobacco pipes of the Portsmouth harbour region: 1680-1932. [S.1.]: [s.n.], 1979.

GARY, Jack. Material culture and multi-cultural interaction at Sylvester Manor. Northeast bistorical archaeology, v. 36, n. 1. p. 100-112, 2007.

GOJAK, Denis; STUART, Iain. The potential for the archaeological study of clay tobacco pipes from Australian sites. Australasian Historical Archaeology, v. 17, p. 38-49, 1999.

HAMMOND, Peter. The London commercial agents of French clay pipe manufacturers Fiolet and Audebert Fiolet. Society for clay pipe research, Bristol: [s.n.], newsletter 15, 1987.

HANSON, Lee. Kaolin pipe stems: Boring in on a fallacy. In: SOUTH, Stanley (Ed.). The conference on Historic Archaeology papers (1969). Columbia: The Institute of Archeology and Anthropology of The University of South Carolina, 1971, p. 2-15. 4 v.

HARRINGTON, Jean. Dating stem fragments of Seventeenth and Eighteenth century clay tobacco pipes. In: SCHUYLER, Robert (Ed.). Historical Archaeology: A guide to substantive and theoretical contributions. New York: Bayood Publishing Copany Inc., 1978, p. 63-65. 
HEARFIELD, John. How much was the loaf of bread. [S.1.]: [s.n.], 2009. Disponível em: <http:// www.johnhearfield.com/History/Breadt.htm>. Acesso em: 22 mar. 2016.

HEIGHTON, R e DEAGAN, K.. A New Formula for Dating Kaolin Clay Pipestems. The Conference on Historic Site Archaeology Papers. V. 6, p. 220-229. 1971.

HERVA, Vesa-Pekka; NURMI, Risto. Beyond Consumption: Functionality, Artifact Biography, and Early Modernity in a European Periphery. International Journal of Historical Archaeology, v. 13 , n. 2 , p. 158-182, jun. 2009.

HIGGINS, David. Clay tobacco pipes: a valuable commodity. The International Journal of Nautical Archaeology, [S.1.]: [s.n.], v. 24, n. 1, p. 47-52, 1995.

England. (Ed.). Journal of the Académie Internationale de la Pipe: National Clay Pipe Summaries, v. 2, p. 41-50, 2009.

Clay tobacco pipes: Specialist Report. In: BROWN, Richard; HARDY, Alan; Brown Alison. Trade and Prosperity, War and Poverty: An Archaeological and Historical Investigation into Southampton's French Quarter. Oxford: Oxford Archaeology, Oxford, p. 199-207, 2011. $15 \mathrm{v}$.

HISSA, Sarah. Tempo e arqueologia: experiências materiais e imateriais de Antártica. Belo Horizonte, 2012. 122 f. Dissertação (Mestrado) - Departamento de Antropologia, Universidade Federal de Minas Gerais.

HUME, Ivor Noël. Artifacts of Colonial America. New York: Alfred A. Knopf, 1985.

. Hunting for a Little Ladle: tobacco pipes. Colonial WilliamsburgJournal, Williamsburg (USA): Colonial Williamsburg Foundation, Winter 2003-2004.

HUMPHREY, Richard. Clay pipes from old Sacramento. Historical Archaeology, New York, Society for Historical Archaeology, v. 3, p. 12-33, 1969.

JACKSON, Reg; BECKEY, Ian; BAKER, Mike. Two groups of nineteenth century pipe waste from Bristol. In: JACKSON, Reg; JACKSON, Philomena (Ed.). Clay pipe research. Bristol, v. 2, 1991.

JAGIELSKI, Lauren. Consumerism in the Late Eighteenth Century: The Treatment of Disposed Tobacco Pipes from the Mount Pleasant Site (46JF215) Jefferson County, West Virginia. $U W-L$ Journal of Undergraduate Research, La Crosse (USA): University of Wisconsin, v. XIII, p. 1-39, 2010.

JEPSON, W. B.; ROWSE, J B. The composition of Kaolinite - An electron microscope microprobe study. Clays and Clay Minerals, Oxford: Pergamon Press, v. 23, p. 310-317, 1975. 
JOHNSON, Mathew. An archaeology of capitalism. Oxford: Blackwell Publishers, 1996.

KIERNAN, Victor. Tobacco: a history. Londres: Hutchinson Radius, 1991.

KLUTTIG-ALTMANN, Ralf. New technologies in the manufacture of clay tobacco pipes in central Europe. Historical Archaeology in Central Europe, Germantown (USA): Society for Historical Archaeology, n. 10, p. 295-304, 2013. Special publication.

; MEHLER, Natascha. Die Emanzipation der deutschen Tonpfeifenforschung. In: UNTERMANNHARTBAUER, Matthias; JANSEN, Michaela (Ed.). Archäologie der frühen Neuzeit. Paderborn: Mitteilungen der Deutschen Gesellschaft für Archäologie des Mittelalters und der Neuzeit, 2007.

LÉVÊQUE, Laura. Deux pipes figurant des personnages sur une bicyclette: Une curieuse collecion. Musée de L'Hôtel Sandelin, Saint-Omer, v. 8, n. 8, p. 1-2, 2014.

LUCKENBACH, Al. The Swan Cove Kiln: Chesapeake Tobacco Pipe Production, Circa 16501669. [s.n.t.] Disponível em: <http://www.chipstone.org/article.php/171/Ceramics-inAmerica-2004/The-Swan-Cove-Kiln:-Chesapeake-Tobacco-Pipe-Production,-Circa-1650---1669-> Acesso em: $1^{\circ}$ fev. 2016.

; KISER, Taft. Seventeenth-Century tobacco pipe manufacturing in the Chesapeake region: A preliminary delineation of makers and their styles. [S.1.]: [s.n.], 2006. Disponível em: <http://www.chipstone.org/article.php/294/Ceramics-in-America-2006/Seventeenth-CenturyTobacco-Pipe-Manufacturing-in-the-Chesapeake-Region:-A-Preliminary-Delineation-of-Makersand-Their-Styles>. Acesso em: 20 jun. 2016.

; SHARPE, Shawn. A seriation analysis of 'trade' and 'belly bowl' tobacco pipe forms from ca. 1655 to ca. 1725. Maryland Archaeology, Annapolis (USA), v. 43, n. 1, p. 28-33, 2007.

MACFARLANE, Helen; MORTIMER-LEE, Paul. Inflation over 300 years. [S.1.]: [s.n.], May 1994. Disponível em: <http://www.bankofengland.co.uk/archive/Documents/historicpubs/qb/1994/ qb940201.pdf>. Acesso em: 22 mar. 2016.

MALLIOS, Seth. Back to the bowl: Using English Tobacco Pipebowls to Calculate Mean SiteOccupation Dates. Historical Archaeology, New York: Society for Historical Archaeology, v. 39, n. 2, p. 89-104, 2005.

MCMILLAN, Lauren. Put this in your pipe and smoke it: An evaluation of tobacco pipe stem dating methods. Greenville, 2010. 102 f. Dissertação (Mestrado) - East Carolina University.

MEHLER, Natascha. Clay pipes in Bavaria and Bohemia: common ground in the cultural and political history of smoking. Studies in Post-Medieval Archaeology, [S.I.]: [s.n.], n. 3, p. 317-336, 2009a. 
The archaeology of mercantilism: clay tobacco pipes in Bavaria and their contribution to an economic system. Studies in Post-Medieval Archaeology, [S.1.]: [s.n.], v. 43, n. 2, p. 261-281, 2009b.

MELLO, Ivani Souza et al. Revisão sobre argilominerais e suas modificações estruturais com ênfase em aplicações tecnológicas e adsorção. Revista de Ciências Agroambientais, Alta Floresta: Unemat, v. 9, n. 1, p. 141-152, 2011.

MEULEN, Jan van der. Goudse Pijpenmakers en bun merken: Pijpelogische kring Nederland, Leiden: Stedelijke Musea Gouda, 2003.

MOLONEY, Brenna. Clay pipes and the social and economic landscape of $19^{\text {th }}$ century. Detroit: Wayne State University, 2013.

MONROE, J. Cameron; MALLIOS, Seth. A seventeenth-century colonial cottage industry: New evidence and a dating formula for colono tobacco pipes in the Chesapeake. Historical Archaeology, New York: Society for Historical Archaeology, v. 38, n. 2, p. 68-82, 2004.

; EMMETT, Quinn. A dating formula for colono tobacco pipes in the Chesapeake.

The Journal of the Jamestown Rediscovery Center, [S.1.]: [s.n.], v. 2, 2004.

MURPHY, James. Shaker reed stem tobacco pipes. Pennsylvania archaeologist, DuBois (USA): Society for Pennsylvania Archaeology, v. 48, n. 1-2, p. 14-52, apr. 1978.

OOSTEVEEN, Jan van. Gorinchem, Krijtstraat: tabakspijpen. [S.1.]: [s.n.], 2011. Disponível em: <http://www.academia.edu/5198842/Gorinchem_Krijtstraat_tabakspijpen>. Acesso em: 28 maio 2015.

Gorinchem, Keizerstraat 44a ${ }^{a}$ Tabakspijpen. [S.1.]: [s.n.], 2012. Disponível em: <http:// www.academia.edu/4701191/Gorinchem_Keizerstraat_44a_Tabakspijpen>. Acesso em: 28 maio 2015.

Kleipijpen: een statistische analyse. Westerheem: tijdschrift voor de Nederlandse archeologie, [S.1.]: [s.n.], v. 50, n. 1, p. 13-27. 2001.

Tabakspijpen van de opraging Blijenhoek te Gorinchem. [S.1.]: [s.n.], 2009. Disponível em: <Academia.edu>. Acesso em: 28 maio 2015.

OSWALD, Adrian. English clay tobacco pipes. Londres: British Archaeological Association, 1967. Clay pipes for the archaeologist. Oxford: British Archaeological Reports, v.

14, 1975. 
PEACEY, Allan; VINCE, Alan. Chemical characterization of clay pipes and wig curlers from Roy's Orchard, Pipe Aston, Herefordshire. Studies in Post-Medieval Archaeology, [S.1.]: [s.n.], v. 37, n. 2, p. 207-216, 2003.

The development of the tobacco pipe kiln in the British Isles. Council for British Archaeology. Internet Archaeology, York (UK): University of York, v. 1, 1996.

PFEIFFER, Michael, GARTLEY, Richaard; SUDBURY, Josh. President pipes: Origin and distribution. The Wyoming archaeologist, Cheyenne (USA): Wyoming Archaeological Society, v. 50, n. 1, p. 9-30, 2006.

PIERCE, Jacqui. Living in Victorian London: the clay pipe evidence. [S.1.]: [s.n.], 2007. Disponível em: <http://www.geog.qmul.ac.uk/victorianlondon/pdf/ClayPipe.pdf>. Acesso em: 28 maio 2015.

PLANELLA, María Teresa et al. Propuesta Integradora para un Estudio del Uso de Plantas con Propiedades Psicoactivas en Pipas del Período Alfarero Temprano y sus Implicancias Sociales. Revista Chilena de Antropología, Santiago: Universidad de Chile, v. 25, n. 1, p. 93-119, 2012.

PRICE, Roger. Distinguishing 'R. Tippet' pipes. Society for clay pipe research, Bristol: [s.n.], Newsletter 1, p. 5-6, 1985.

RECKNER, Paul. Negotiating patriotism at the five points: Clay tobacco pipes and patriotic imagery among trade unionists and nativists in a nineteenth-century New York neighborhood. Historical Archaeology, New York: Society for Historical Archaeology, v. 35, n. 3, p. 103-114, 2001.

; DALLAL, Diane. Tales of five points: Working-class life in Nineteenth-century New York. West Chester (USA): US General Services Administration, 2000.

RICE, Prudence. Pottery Analysis: A Sourcebook. Chicago: The University of Chicago Press, 1987.

RICHIE, Clarence. Nineteenth-Century Clay Tobacco-Pipes from the High Arctic. Canadian Journal of Archaeology, Ottawa: Canadian Archaeological Association, n. 2, p. 123-137, 1978.

RYE, Owen. Pottery Technology: Principles and Reconstruction. Washington: Taraxacum Press, 1981. (Manuals on Archaeology 4).

SCHIVELBUSCH, Wolfgang. Tastes of Paradise: a social history of spices, stimulants, and intoxicants. New York: Pantheon Books, 1992.

SEIFERT, Donna. Within site of the White House: The Archaeology of working women. Historical Archaeology, New York: Society for Historical Archaeology, v. 25, n. 4, p. 82-108, 1991. 
SERGEANT, Thomas; LOWBER, John (Ed). Report cases argued and determined in the English Courts of Common Law. Philadelphia: T \& J W Johnson \& CO; Law Booksellers, 1869. 16 v.

SHARPE, Shawn; LUCKENBACH, Al; KILLE, John. Burle's town land (ca. 1649-1676): a marked abundance of pipes. In: LUCKENBACH, Al (Ed.). The Clay Tobacco Pipe in Anne Arundel County: Maryland (1650-1730). Annapolis (USA): Anne Arundel County Trust for Preservation, 2000.

SHEPARD, Anna. Ceramics for the Archaeologist. Washington: Braun-Brumfield, 1985.

SMITH, Robin. Analysis of The Clay Tobacco Pipe Assemblage from the Front Street Site (AjGu15), Toronto. Ontario Archaeology, Toronto: Ontario Archaeological Society, v. 46, p. 55-61, 1986.

SUDBURY, Byron. Additional notes on alternative uses for clay tobacco pipes and tobacco pipe fragments. Historical Archaeology, New York: Society for Historical Archaeology, v. 12, p. 105107, 1978.

; GERTH, Ellen. The Jacksonville 'bluechina' shipwreck (Site BA02): clay tobacco pipes. Odyssey Marine Exploration Papers, [S.1.]: [s.n.], v. 21, p. 1-23, 2011.

TATMAN, Colin. An alternative use for clay pipes. Society for clay pipe research, Bristol: [s.n.], Newsletter 2, p. 12-13, 1984.

TEICHNER, Felix von. Tonpfeifenbäcker in Berlin und Brandenburg. EAZ, Ethnogr. Archäol. Z, Berlin: [s.n.], v. 39. p. 353-365, 1998.

VINCE, Alan; PEACEY, Allan. Pipemakers and their workshops: the use of geochemical analysis in the study of the clay tobacco pipe industry. In: ARCHER, Steven; BARTOY, Kevin (Ed.). Between dirt and discussion: Methods, Methodology, and Interpretation in Historical Archaeology. New York: Springer, 2006, p. 11-31.

WACKE, Aline. The clay tobacco pipe collection from Hólar, Iceland: a case study. Reykjavík, 2014. 88 f. Dissertação (Mestrado) - Háskóli Íslands.

WALKER, Iain. Alternative uses for clay tobacco pipes and tobacco pipe fragments: some notes. Historical Archaeology, New York: Society for Historical Archaeology, v. 10, p. 124-127, 1976a.

Churchwarden clay tobacco-pipes and the Southorn pipemaking Family of Broseley, Shropshire. The Journal of the Society for Post-Medieval Archaeology, Londres: Society for PostMedieval Archaeology, v. 10, p. 142-149, 1976b.

Nineteenth-century clay tobacco pipes in Canada. Ontario Archaeology, Toronto: Ontario Archaeological Society, n. 16, p. 19-35, 1970. 
The manufacture of Dutch clay tobacco-pipes. Northeast Historical Archaeology, Binghamton (USA): Binghamton University, v. 1, n. 1, p. 5-17, 1971.

WHITE, A. Lancaster clay tobacco-pipes. Contrebis, Lancaster (UK): Lancaster Archaeological and Historical Society, v. 3, n. 2, 1975. Disponível em: <http://www.archaeologyuk.org/lahs/ Contrebis/3-58-White.pdf >. Acesso em: 23 jun. 2017.

WHITE, Susan. Draft guidelines for using the clay tobacco pipe record sheets. In: The Dynamics of Regionalisation and Trade: Yorkshire Clay Tobacco Pipes c1600-1800. Oxford: British Archaeological Reports, 2004, p. 487-490. (BAR British Series, 374).

WYNIA, Katie. The spatial distribution of tobacco pipe fragments at the Hudson's Bay Company Fort Vancouver village site: smoking as a shared and social practice. Portland, 2013. $147 \mathrm{f}$. Dissertação (Mestrado) - Portland State University.

ZARANKIN, Andrés e SENATORE, M. Ximena. Historias de un pasado en Blanco: arqueologia histórica antártica. Belo Horizonte: Argumentum, 2007. 